\title{
REACTION GAMMA RAYS IN PLUTONIUM \\ COMPOUNDS, MIXTURES, AND ALLOYS
}

H. Rodney Martin

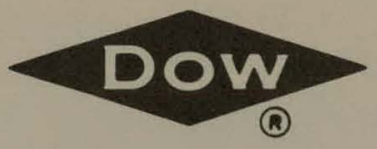

DOW CHEMICAL U.S.A. ROCKY FLATS DIVISION P. O. BOX 888 GOLDEN, COLORADO 80401

U. S. ENERGY RESEARCH AND DEVELOPMENT ADMINISTRATION

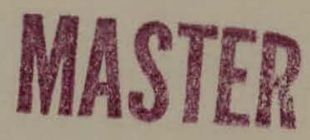
CONTRACT AT(29-1)-1106 


\section{DISCLAIMER}

This report was prepared as an account of work sponsored by an agency of the United States Government. Neither the United States Government nor any agency Thereof, nor any of their employees, makes any warranty, express or implied, or assumes any legal liability or responsibility for the accuracy, completeness, or usefulness of any information, apparatus, product, or process disclosed, or represents that its use would not infringe privately owned rights. Reference herein to any specific commercial product, process, or service by trade name, trademark, manufacturer, or otherwise does not necessarily constitute or imply its endorsement, recommendation, or favoring by the United States Government or any agency thereof. The views and opinions of authors expressed herein do not necessarily state or reflect those of the United States Government or any agency thereof. 


\section{DISCLAIMER}

Portions of this document may be illegible in electronic image products. Images are produced from the best available original document. 


\section{LEGAL NOTICE}

This report was prepared as an account of work sponsored by the United States Government. Neither the United States nor the Energy Research and Development Administration, nor any of their employees, nor any of their contractors, subcontractors, or their employees, makes any warranty, expressed or implied, or assumes any legal liability or responsibility for the accuracy, completeness or usefulness of any information, apparatus, product or process disclosed, or represents that its use would not infringe privately owned rights.

Printed in the United States of America

Available from the

National Technical Information Service

U. S. Department of Commerce

Springfield, Virginia 22151

Price: Printed Copy $\$ 4.00$ Microfiche $\$ 2.25$ 
Printed

June 16, 1975
RFP-2832

UC-4 CHEMISTRY

TID-4500-R62

\title{
REACTION GAMMA RAYS IN PLUTONIUM COMPOUNDS, MIXTURES, AND ALLOYS
}

H. Rodney Martin

Chemistry Research and Development CHEMISTRY INSTRUMENTATION

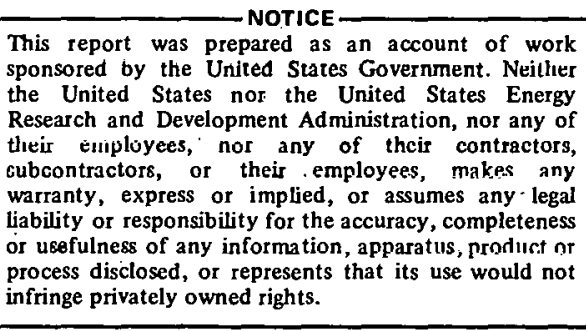

This report was prepared as an account of work sponsored by the United States Government. Neilliter their euployees, cubcontractors, or their employees, makes any Wranty, express or implied, or assumes any legal infringe privately owned rights.

\section{SUBJECT DFSCRIPTORS}

Nuclear Reactions

Plutonium Oxides

Gamma Spectra

Neutrons

\author{
DOW CHEMICAL U.S.A. \\ ROCKY FLATS DIVISION \\ P. O. BOX 888 \\ GOLDEN, COLORADO 80401 \\ Prepered under Contract AT(29-1)-1106 \\ for the \\ Albuquerque Operations Office
}

U.S. Energy Research and Development Administration 
THIS PAGE

\section{WAS INTENTIONALLY \\ LEFT BLANK}




\section{CONTENTS}

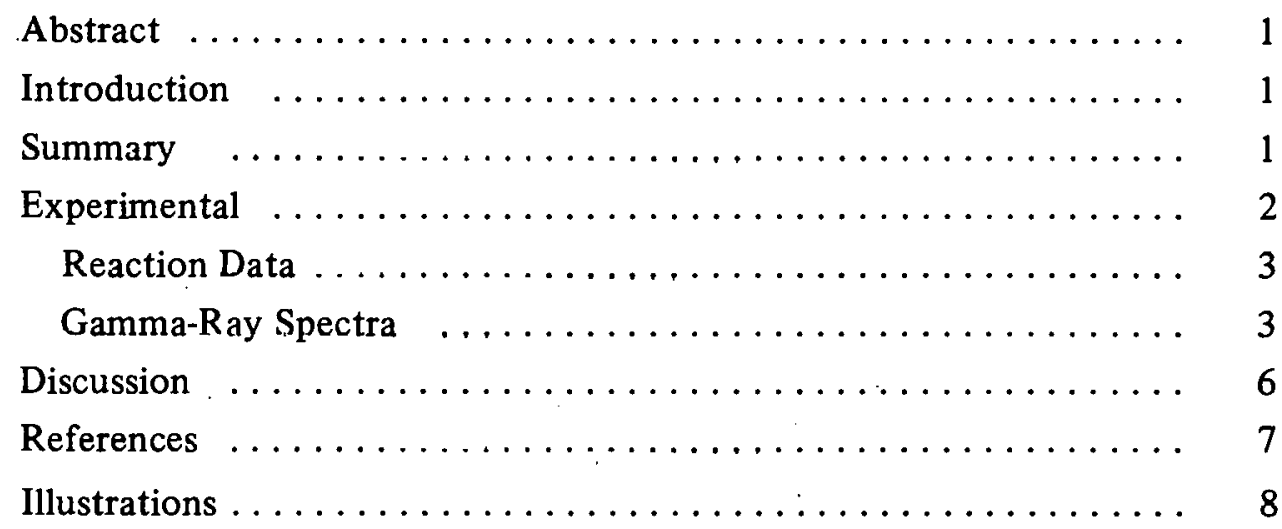

(Figures 1 through 20) 


\section{THIS PAGE \\ WAS INTENTIONALLY \\ LEFT BLANK}




\section{A C K N O W LE D G M E T S}

The author wishes to express his appreciation to several Rocky Flats personnel for their assistance with this project. The author thanks $\mathrm{L}$. W. Doher, J. R. Bradshaw, and J. D. McBride for providing the plutonium dioxide, light-element samples, and acknowledges the many others who provided most of the plutonium compounds and alloys.

Particular thanks go to R. A. Deal who was instrumental in originating this study and who participated in some of the early measurements. Thanks also go to L. A. Bidwell, R. N. Chanda, and C. R. Forrey, Jr. for their assistance during some of the preliminary measurements.

Special consideration goes to M. H. Putnam and S. McClure from Aerojet Nuclear Co., Idaho Falls, Idaho, for providing the Gauss 5 program and for their consultation. Finally, the author thanks the Rocky Flats Computing and Management Science Departments and particularly Y. M. Ferris and G. L. Kaes for their continued support. 


\section{THIS PAGE}

\section{WAS INTENTIONALLY LEFT BLANK}




\title{
REACTION GAMMA RAYS IN PLUTONIUM COMPOUNDS, MIXTURES, AND ÁLLOYS
}

\author{
H. Rodney Martin
}

\begin{abstract}
Gamma-ray spectra for 15 light elements, from lithium $(Z=3)$ to potassium $(Z=19)$, in plutonium compounds, mix tures, and alloys have been obtained with germanium (lithium) detectors. Reaction gamma rays produced by plutonium alpha particle bombardment of light elements have been identified and characterized by energy and production mode in the spectra. Neutron emission rates, relative to a plutonium dioxide standard, are also reported for several mixtures involving plutonium dioxide and light elements.
\end{abstract}

\section{INTRODUCTION}

The use of alpha radioactive materials in nuclear weapons, fissionable fuel, and isotopic power sources has increased dramatically in recent years. In most applications, the elimination or identification of neutrons and gamma rays from sources other than the natural alpha emitter is desirable. Nuclear reactions produced from alpha bombardment of light elements provide a major source of "nonnatural" neutrons and gamma rays. The principal reactions occuring in alpha-emitting materials are of the type $(a, \mathrm{n} \gamma),(a, \mathrm{p} \gamma)$, and $\left(a, a^{\prime} \gamma\right)$. The gamma rays result from de-excitation of the excited nucleus following a nuclear reaction, and they are designated as reaction gamma rays. These gamma rays have distinct energies, and they can be used to identify light elements once the energies and yields of the reaction gamma rays are known.

The probability that a reaction will occur is dependent on the incident alpha-particle energy. First, the alpha energy must satisfy a threshold value necessary to produce a nuclear reaction; secondly, it must be sufficient to penetrate the potential barrier produced by Coulomb repulsion between the two positively charged, reactant nuclei.

From a quantum-mechanical picture, an alpha particle can tunnel through the barrier rather than going over the top. For this reason, reactions can sometimes be observed when the incident alphaparticle energy is less than the barrier height. Since the height of the barrier increases with increasing atomic number, reactions with appreciable probabilities are limited to the lighter elements with $Z<20$ for most common alpha emitters.

The identification of reaction gamma rays and neutrons is important in nuclear facilities both from shielding and waste/scrap assay viewpoints. Most reaction gamma-ray studies on light elements have been carried out with positive ion accelerators; however, the alpha-bombarding energies in these investigations usually were not in the region applicable to natural alpha emitters, and the results are not available in catalog form.

McKibben ${ }^{1}$ has reported previously on neutron and sodium iodide (thallium) $[\mathrm{NaI}(\mathrm{T} 1)]$ gamma-ray measurements obtained from plutonium oxide $\left({ }^{238} \mathrm{PuO}_{2}\right)$ mix tures with light-element compounds. Gamma-ray spectra for 15 light elements in plutonium compounds, mix tures, and alloys obtained with germanium (lithium) [Ge(Li)] detectors are presented in this report. $\mathrm{Ge}(\mathrm{Li})$ measurements should provide more information than $\mathrm{NaI}(\mathrm{Tl})$ measurements because of the detector's superior resolution. A catalog was prepared as an aid in identifying and explaining the presence of reaction gamma rays and neutrons in waste materials from multiple possible assortments of light elements.

\section{SUMMARY}

Reaction neutrons and gamma rays arise from alpha-particle bombardment of certain light elements in combination with plutonium and other alpha emitters. These gamma rays have distinct and characteristic energies that provide a 
rapid and highly specific method for the identification and qualitative analysis of light elements contained in alpha-emitting materials. These elements include: lithium ( $\mathrm{Li})$, beryllium $(\mathrm{Be})$, boron $(B)$, nitrogen $(N)$, fluorine $(F)$, sodium $(\mathrm{Na})$, magnesium $(\mathrm{Mg})$, aluminum (Al), phosphorus $(\mathrm{P})$, chlorine $(\mathrm{Cl})$, and potassium $(\mathrm{K})$.

The gamma-ray spectra reveal that reaction gamma rays from light elements, with the exception of fluorine in plutonium tetrafluoride, are not of sufficient intensity to cause appreciable interferences in passive, plutonium-assay systems based on the plutonium " $384 \mathrm{keV}$ " gamma-ray region. The presence of the light elements $\mathrm{Li}, \mathrm{Be}, \mathrm{B}, \mathrm{C}, \mathrm{F}, \mathrm{Na}$, $\mathrm{Mg}$, and $\mathrm{Al}$ can cause significant increases $(>10 \%)$ in neutron emission rates. Except for graphite carbon, all of these elements are also prolific, reaction gamma-ray emitters, and their presence can be détermined by Nal('I'l) or Ge(Li) gamma counting.

Reaction gamma rays have been observed in a variety of materials exhibiting unusual neutron or gamma-ray counts, and the catalog has proven useful in explaining these results. The spectra have also provided information that aids in understanding potential pitfalls of passive assay systems.

\section{EXPERIMENTAI.}

Reaction gamma-ray spectra have been accumulated for 15 light elements from two different types of samples. The first group involved plutonium compounds and alloys containing an abundance of one light element. Special attention was given to eliminating or identifying impurity elements of low atomic numbers in this group.

The second group of samples was prepared by mixing $\mathrm{PuO}_{2}$ samples with various compounds containing light elements. These mixtures are prepared more easily than most compounds or alloys of plutonium light elements. They should also be more representative of the distribution of plutonium and light elements in waste materials since mixtures would occur more frequently than compounds or alloys (excluding specific plutonium tetrafloride waste).

The mixtures were prepared by weighing 20 grams of dry, reagent-grade compound (usually pulverized to less than $100 \mathrm{mesh}$ ) into a 1-in.-diameter by 3-in.-high polystyrene vial. Five grams of plutonium were added by adding 5.68 grams of $\mathrm{PuO}_{2}$ standard. This vial was then sealed and placed on a paint shaker for 15 to 20 minutes to homogenize the sample. Finally, the vial was placed into an outer polystyrene vial $1.5 \mathrm{in}$. in diameter by 4 in. high.

Gamma-ray spectra were obtained with a $4 \%$ efficient $\mathrm{Ge}(\mathrm{Li})$ detector having a resolution of $2.0 \mathrm{keV}$ at $1332 \mathrm{keV}$ and with a 40.96 shannel Nuclear Data 50/50 analyzer. Samples were contained in polystyrene vials as described above or were mounted on cards between layers of mylar. Sourcc-to-detcitori dislantes of fruIll 1 to $13 \mathrm{~cm}$ were employed, with the distances being measured from the edge closest to the detector for samples contained in vials. The samples were placed in such a manner that a horizontal line passing through the renter of the detector would pass through the midpnint of the sample. Most samples were counted with a 0.063-in. cadmium absorber placed over the detector face. The cadmium effectively reduces the intensity of the $60 \mathrm{keV}^{241} \mathrm{Am}$ (americium) gamma ray, reducing instrumental deadtime, which permits the counting of more Pu samples.

The gamma-ray spectra were analyzed using the Gauss 5 computer program. ${ }^{2}$ This program provides a method for analyzing gamma-ray spectra measured with a $\mathrm{Ge}(\mathrm{Li})$ spectrometer. The analysis involves a nonlinear, least squares fit of the gammaray peak(s) by one or more Gaussian data functions and by the determination of a background line that represents the underlying Compton continuum. In some cases, the program would analyze the Doppler-broadened reaction gamma rays as doublets, triplets, and so forth, requiring a hand analysis of these gamma rays. Figures were obtained using various spectra plot computer programs.

Neutron measurements were carried out with a neutron system containing eight 1 -in. diameter by 
12-in. long ${ }^{3} \mathrm{He}$ (helium) detectors filled to four atmospheres pressure. The detectors were spaced equally around a 7 -in. diameter hole in the center of a 1-foot by 1 -foot polyethylene slab. This assembly was surrounded by a 2 -in.-thick polyethylene slab. The samples were placed in the center hole equidistant from the midpoint of each neutron detector.

\section{Reaction Data}

Table 1 presents reaction data accumulated for the 15 light elements examined in this investigation. The reactant light elements, arranged according to increasing atomic number, and the compounds employed in the mixtures of $\mathrm{PuO}_{2}$. and light elements are listed in Columns 1 and 2, respectively.

Column 3 gives the ratio of the neutron count from the $\mathrm{PuO}_{2}$ mixtures relative to a five-gram $\mathrm{PuO}_{2}$ source. The neutron ratios provide an order-ofmagnitude indicator for mixtures of plutonium oxide with light elements. These results have an inherent dependency on the detection efficiency of the ${ }^{3} \mathrm{He}$ neutron detectors and are not corrected for differences in the neutron-energy spectra.

Column 4 of Table 1 presents the major reaction gamma rays associated with each light element, arranged according to increasing energy. Column 5 lists the most probable nuclear reaction for producing the observed gamma ray. In Column 4, some of the major reaction gamma rays from a particular light element are rated on an intensity code relative to the $413 \mathrm{keV}$ gamma ray observed in the decay of ${ }^{239} \mathrm{Pu}$. The code contains the ratings $0,1,2$, and 3 , which indicate intensities, relative to the $413 \mathrm{keV}$ gamma ray, of $>10 \%$, 1 to $10 \%, 0.1$ to $1 \%$, and 0.01 to $0.1 \%$, respectively. Note, however, that sample or container absorption corrections have not been applied to these intensities.

The detection of weak reaction gamma rays with energies below about $800 \mathrm{keV}$ is uncertain because of the greater abundance of low-energy gamma rays observed in the decay of ${ }^{239} \mathrm{Pu}$. Estimates indicate reaction gamma rays with intensities, relative to the $375 \mathrm{keV}^{239} \mathrm{Pu}$ gamma ray, of $<5 \%$, and $<1 \%$ may not have been detected in the energy regions $<500 \mathrm{keV}$ and 500 to $800 \mathrm{keV}$, respectively. This assumes the reaction gamma ray has a resolvable energy separation from decay gamma rays. In cases where the nuclear level schemes indicated the probable presence of a low-energy reaction gamma ray, efforts were made to identify this line; for example, the 197 and $440 \mathrm{keV}$ lines produced by alpha bombardment of fluorine and sodium, respectively.

\section{Gamma-Ray Spectra}

A listing of the spectra is given in Table 2. Only the $\mathrm{PuO}_{2}$ mixtures are listed in Table 2; however, reaction gamma-ray energies and elemental assignments were based on the spectra obtained from all samples. The gamma-ray spectra are presented in Figures 1 through 19.* Spectra from $\mathrm{PuO}_{2}$ mixtures are shown in Figures 1. through 14, those from plutonium compounds and alloys in Figures 15 through 18, and a spectrum from a light-element mixture is presented in Figure 19.

Reaction gamma rays in Figures 1 through 19 are denoted by the product nucleus, while single and double escape lines are labeled by $\mathrm{S}$ and $\mathrm{D}$, respectively. In cases where several reactionproduct nuclei are possible, each possibility is listed. Assignments for gamma rays having a high degree of uncertainty are enclosed in parentheses. The cadmium absorber has already been described in this report; the geometry indicates a source-todetector face distance.

Most gamma-ray peaks in the spectra are described by four to six channels of data at these gain settings. Peak shifts of one or two channels are sometimes observed between sample and background counts because of the higher count-rate from the sample. Because of these gain shifts and because background interferences are minimal in $\mathrm{Ge}(\mathrm{Li})$ spectra, background lines were not subtracted from any of the spectra.

\footnotetext{
*See Figures 1 through 20 at end of text.
} 
TABLE 1. Summary of Reaction Data.

\begin{tabular}{|c|c|c|c|c|c|}
\hline Element & Compound & $\begin{array}{c}\text { Neutron Ratio } \\
\left(\text { Mixture } / \mathrm{PuO}_{2}\right)^{*}\end{array}$ & $\begin{array}{c}\text { Major Reaction } \\
\text { Gamma Rays } \\
\text { (keV) }\end{array}$ & & obable Source \\
\hline Li (lithium) & $\mathrm{Li}_{2} \mathrm{CO}_{3}$ (lithium carbonate) & 1.58 & $479(0)^{* *}$ & ${ }^{7} \mathrm{Li}$ & $\left(a, a^{\prime}\right){ }^{7} \mathrm{Li}$ \\
\hline $\mathrm{Be}$ (beryllium) & $\mathrm{BeO}$ (beryllium oxide) & 71.5 & 4432 & ${ }^{9} \mathrm{Be}$ & $(a, n){ }^{12} \mathrm{C}$ \\
\hline B (boron) & $\mathrm{H}_{3} \mathrm{BO}_{3}$ (orthoboric acid) & 9.43 & 2312 & ${ }^{11} \mathrm{~B}$ & $(a, n){ }^{14} \mathrm{~N}$ \\
\hline & & & $3684(2)$ & ${ }^{10} \mathrm{~B}$ & $(a, p){ }^{13} \mathrm{C}$ \\
\hline & & & $3854(2)$ & ${ }^{10} \mathrm{~B}$ & $(a, p){ }^{13} \mathrm{C}$ \\
\hline$C$ (carbon) & Graphite & 1.14 & None detected & & \\
\hline$N($ nitrogen) & Urea & 1.01 & $871(2)$ & ${ }^{14} \mathrm{~N}$ & $(a, p){ }^{17} \mathrm{O}$ \\
\hline & $\left(\mathrm{NH}_{4}\right)_{2} \mathrm{HPO}_{4}$ (ammonium orthophosphate, mono-H) & 1.03 & $871(2)$ & ${ }^{14} \mathrm{~N}$ & $(a, p){ }^{17} 0$ \\
\hline$O($ oxygen) & None & 1.0 & 1395 & ${ }^{18} \mathrm{O}$ & $(a ; n){ }^{21}$ No (noon) \\
\hline & & & 1634 & ${ }^{17} n$ & $(n, n){ }^{20} \mathrm{Ne}$ \\
\hline & & & 2438 & io $U$ & $(a, n)^{i i} \mathrm{Ne}$ \\
\hline & & & 2790 & ${ }^{18} \mathrm{O}$ & $(a, \mathrm{n}){ }^{21} \mathrm{Ne}$ \\
\hline F (florine) & $\mathrm{CaF}_{2}$ (calcium fluoride) & 10.81 & 197 & ${ }^{19} \mathrm{~F}$ & $\left(a, a^{\prime}\right)^{19} \mathrm{~F}$ \\
\hline & & & $583(1)$ & ${ }^{19} \mathrm{~F}$ & $(a, \mathrm{n}){ }^{22} \mathrm{Na}$ (sodium) \\
\hline & & & $891(2)$ & ${ }^{19} \mathrm{~F}$ & $(a, \mathrm{n}){ }^{22} \mathrm{Na}$ \\
\hline & $\cdot$ & & $1236(2)$ & ${ }^{19} \mathrm{~F}$ & $\left(a, a^{\prime}\right)^{19} \mathrm{~F}$ \\
\hline . & & & $1275(1)$ & ${ }^{19} \mathrm{~F}$ & $(a, p){ }^{22} \mathrm{Ne}$ \\
\hline & & & 1350 & ${ }^{19} \mathrm{~F}$ & $\left(a, a^{\prime}\right)^{19} \mathrm{~F}$ \\
\hline & . & & 1360 & ${ }^{19} \mathrm{~F}$ & $\left(a, a^{\prime}\right)^{19} \mathrm{~F}$ \\
\hline & & & 1401 & ${ }^{19} \mathrm{~F}$ & $(a, n)^{22} \mathrm{~N}_{a}$ \\
\hline & & & 1460 & ${ }^{19} \mathrm{~F}$ & $\left(a, a^{\prime}\right)^{19} \mathrm{~F}$ \\
\hline & & & $1538(2)$ & $19 \mathrm{~F}$ & $(a, n) \stackrel{22}{2} \mathrm{Na}$ \\
\hline & & & 1554 & ${ }^{19} \mathrm{~F}$ & $(a, n){ }^{22} \mathrm{Na}$ \\
\hline & & & $2080(3)$ & ${ }^{19} \mathrm{~F}$ & $(a, p){ }^{22} \mathrm{Ne}$ \\
\hline & & & 3180 & ${ }^{19} \mathrm{~F}$ & $(a, p) \quad{ }^{22} \mathrm{Ne}$ \\
\hline $\mathrm{Na}$ (sodium) & $\mathrm{Na}_{2} \mathrm{CO}_{3}$ (sodium carbonate) & 2.36 & $400(1)$ & ${ }^{23} \mathrm{Na}$ & $\left(a, a^{\prime}\right)^{23} \mathrm{Na}$ \\
\hline & & & $1003(3)$ & ${ }^{23} \mathrm{Na}$ & $(a, \mathrm{p}){ }^{26} \mathrm{Mg}$ \\
\hline & & & $1129(2)$ & ${ }^{23} \mathrm{Na}$ & $(a, p){ }^{26} \mathrm{Mg}$ \\
\hline
\end{tabular}

*Contains 133 ppm americium-241.

**See text for explanation of gamma-ray intensities.

The most intense background lines from natural sources and the probable assignments of the lines are given in Table 3 . In addition, a $1274 \mathrm{keV}$ background line was observed in the $\mathrm{PuO}_{2}$ compound mixtures. This line appeared shortly before the start of these measurements and disappeared shortly after their conclusion. It is probably associated with ${ }^{22} \mathrm{Na}$ and is also included in Table 3.

Some gamma rays observed in the spectra obtain from samples with the highest neutron yield; 
TABLE 1. (continued).

\begin{tabular}{|c|c|c|c|c|}
\hline Element & Compound & $\begin{array}{l}\text { Neutron Ratio } \\
\left.(\text { Mixture/PuO })_{2}\right)^{*}\end{array}$ & $\begin{array}{l}\text { Major Reaction } \\
\text { Gamma Rays } \\
(\mathrm{keV})\end{array}$ & Probable Source \\
\hline $\mathrm{Na}$ (sodium) & $\mathrm{Na}_{2} \mathrm{CO}_{3}$ (sodium carbonate) & 2.36 & $\begin{array}{l}1779(3)^{*+} \\
1809(2) \\
2131 \\
2938\end{array}$ & 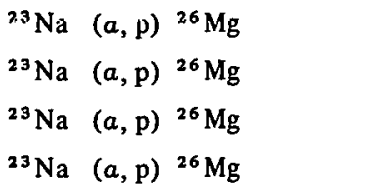 \\
\hline Mg (magnesium) & $\mathrm{MgSO}_{4}$ (magnesium sulfate) & 1.43 & $\begin{array}{l}844(3) \\
1013(3) \\
1779(3) \\
2028 \\
2428 \\
2838\end{array}$ & $\begin{array}{l}{ }^{24} \mathrm{Mg}(a, \mathrm{p}){ }^{27} \mathrm{Al} \text { (aluminum) } \\
{ }^{24} \mathrm{Mg}(a, \mathrm{p}){ }^{27} \mathrm{Al} \\
{ }^{24} \mathrm{Mg}\left(a, a^{\prime}\right){ }^{24} \mathrm{Mg} \\
{ }^{25} \mathrm{Mg}(a, n){ }^{28} \mathrm{Si} \text { (silicon) } \\
{ }^{26} \mathrm{Mg}(a, n){ }^{29} \mathrm{Si} \\
{ }^{26} \mathrm{Mg}(a, n){ }^{29} \mathrm{Si} \\
{ }^{25} \mathrm{Mg}(a, n){ }^{28} \mathrm{Si}\end{array}$ \\
\hline $\mathrm{Al}$ (aluminum) & $\mathrm{Al}_{2} \mathrm{O}_{3}$ (aluminum oxide) & 1.48 & $\begin{array}{l}1262(2) \\
1311 \\
1552(3) \\
2235(2) \\
2594 \\
3045 \\
3498 \\
4809\end{array}$ & 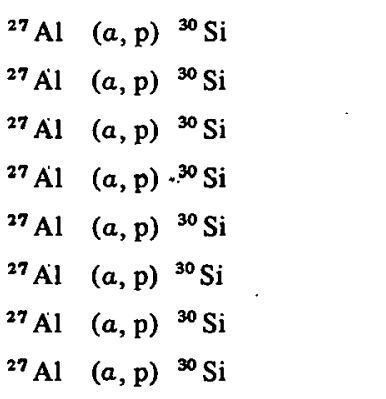 \\
\hline Si (silicon) & $\mathrm{SiO}_{2}$ (silicon oxide) & 1.08 & None detected & \\
\hline P (phosphorus) & $\left(\mathrm{NH}_{4}\right)_{2} \mathrm{HPO}_{4}$ (ammonium orthophosphate, mono-H) & 1.03 & $\begin{array}{l}2127(3) \\
3310\end{array}$ & $\begin{array}{ll}{ }^{31} \mathrm{P} & (a, \mathrm{p}){ }^{34} \mathrm{~S} \text { (sulfur) } \\
{ }^{31} \mathrm{P} & (a, \mathrm{p}){ }^{34} \mathrm{~S}\end{array}$ \\
\hline S (sulfur) & Sulfur Powder & 0.94 & None detected & \\
\hline $\mathrm{Cl}$ (chlorine) & $\mathrm{CaCl}_{2}$ (calcium chloride) & 0.98 & $\begin{array}{l}1209 \\
1643 \\
2168(3)\end{array}$ & $\begin{array}{ll}{ }^{35} \mathrm{Cl} & (a, p) \cdot{ }^{38} \mathrm{Ar} \text { (argon) } \\
{ }^{35} \mathrm{Cl} & (a, p){ }^{38} \mathrm{Ar} \\
& (a, p){ }^{38} \mathrm{Ar}\end{array}$ \\
\hline $\mathrm{K}$ (potassium) & $\mathrm{K}_{2} \mathrm{CO}_{3}$ (potassium carbonate) & 1.03 & 1524 & ${ }^{39} \mathrm{~K} \quad(a, \mathrm{p}){ }^{42} \mathrm{Ca}$ (calcium) \\
\hline
\end{tabular}

*Contains 133 ppm americium-241.

** See text for explanation of gamma-ray intensities.

i.e., beryllium oxide $(\mathrm{BeO})$, orthoboric acid $\left(\mathrm{H}_{3} \mathrm{BO}_{3}\right)$, and plutonium tetrafloride $\left(\mathrm{PuF}_{4}\right)$, originate from the surrounding materials. These gamma rays, in the energy range of 800 to 2000 $\mathrm{keV}$, are attributed to neutron inelastic scattering in the lead shield, the copper liner used in the shield, and in the aluminum housing around the detector. A summary of the gamma rays assigned to the lead, copper, and aluminum in these spectra is also given in Table 3. 
TABLE 2. Presentation of Gamma-Ray Spectra (Figures 1-20 following Table 3).

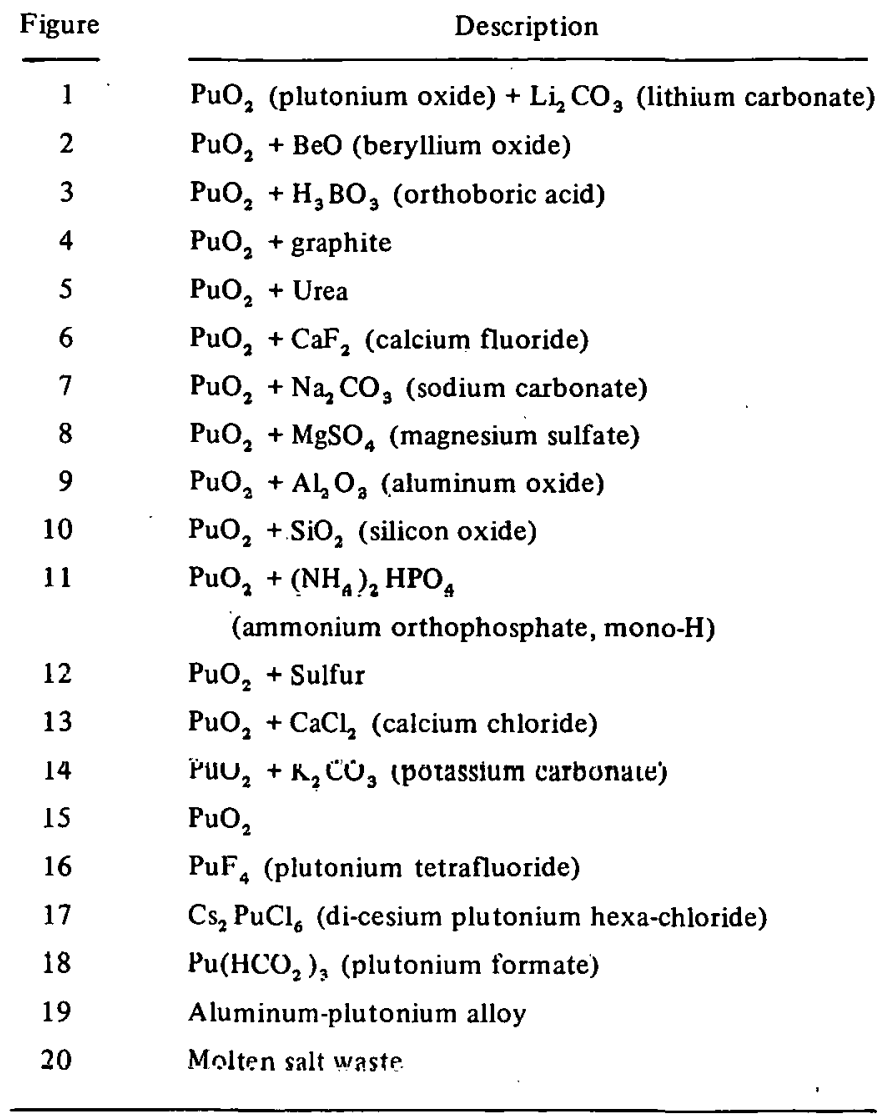

Several of the spectra having low-intensity reaction gamma rays have observable lines at 1395, 1634, and $2438 \mathrm{keV}$. These lines result from alpha reactions on the oxygen in the plutonium dioxide. They are not labeled in the spectra since they do not originate from the light-element compound employed in the sample.

\section{DISCUSSION}

Absolute emission rates for neutrons or gamma rays are not reported herein. The absolute emission rates or reaction rates are determined largely by the number and the average incident energy of the alpha particles. The nuclear, physical, and chemical properties of the sample play an important role in the emission rates. All three properties can
TABLE 3. Summary of Gamma Rays Assigned to Background and to the Shielding.

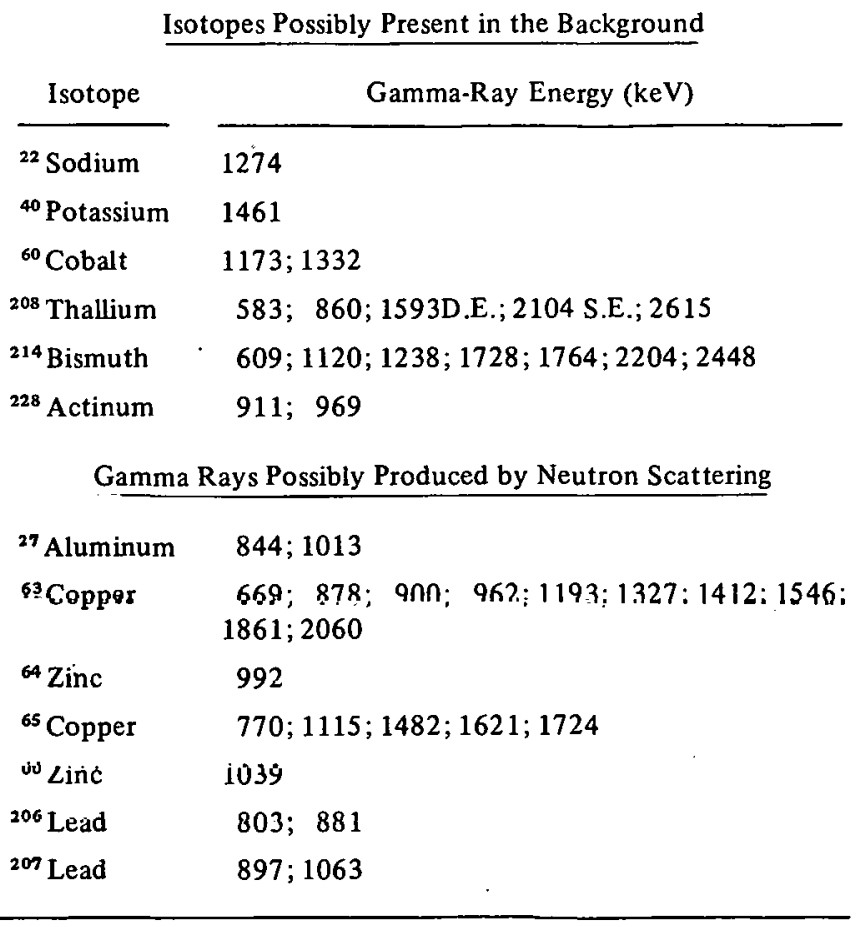

significantly influence the number of alpha particles incident on a partirular light element with an energy sufticient to producc a nuclear reaction.

Nuclear properties that influence emission rates include variations in the plutonium isotopic composition, the ${ }^{241} \mathrm{Am}$ concentration, and the concentration of alpha-emitting impurities in the sample. Physical properties consist of differences in particle size, the degree of mixing, and the density of the mixtures. Chemical properties include differences in the stochiometric composition, the inter-atomic distances, and the density of the compound. These factors mean the absolute rates would not be useful quantities except for almost ideal matchups between standards and samples.

In the present samples, the intensity of reaction neutrons and gamma rays will be reduced in the mixtures as compared with the compounds or alloy" This is caused primarily by physical considerations. The distance between the plutonium atom(s) and 
the light-element atom(s) in the mixtures is greater than in the compounds and will usually contain some nonreacting, intermediate atom that can cause the alpha particle to lose energy by ionization and excitation processes. Therefore, in the mixtures, there is a lower probability that the alpha particle will collide with the light element or will have sufficient energy to produce a reaction in the event of a collision. For example, one finds the $1275 \mathrm{keV}$ reaction gamma ray observed in the plutonium dioxide, calcium fluoride mixture is reduced to $8 \%$ of its intensity in the $\mathrm{PuF}_{4}$ sample, although the actual fluorine content is six times greater in the mixture.

Gamma-ray spectra obtained from some plutonium compounds, alloys, and waste materials were obtained prior to those from the mixtures. In these earlier spectra, several reaction products with $Z<20$ were observed as possibilities, although assignment to a particular light element was difficult. In almost all cases, these multiple assignments were clarified by comparison with the spectra obtained from mixtures of plutonium oxide and light elements. This points out the difficulty in assigning the reaction gamma rays without a catalog of light-element spectra.

Figure 20 illustrates the potential usefulness of the catalog. The majority of the reaction gamma rays arise from ${ }^{23} \mathrm{Na}(a, \mathrm{p} \gamma){ }^{26} \mathrm{Mg}$ reactions. The gamma rays at 1524 and $2167 \mathrm{keV}$ are assigned to alpha reactions on ${ }^{39} \mathrm{~K}$ and ${ }^{35} \mathrm{Cl}$, respectively, and the $1779 \mathrm{keV}$ line is assigned to an alpha reaction on ${ }^{25} \mathrm{Mg}$. The molten salt contains large amounts of sodium chloride and potassium chloride, and a lesser amount of magnesium chloride. In this case, the reaction gamma rays do provide a means of identification and a qualitative estimate of the relative abundance of these light elements.

Reaction gamma rays do not always appear as expected. A particular reaction gamma ray's appearance or absence is not necessarily related to the light-element abundance of the total sample. For example, spectra from a magnesium oxide crucible used in a molten salt operation were dominated by sodium reaction gamma rays. In this case, the results would indicate that within the crucible, the plutonium and sodium salt are absorbed into the wall and are in closer contact than the plutonium with the magnesium. Results of this type clearly reveal the intimate contact necessary before reactions occur, also the difficulties one may encounter in trying to predict alpha reactions in inhomogeneous materials.

\section{REFERENCES}

1. J. M. McKibben, Nucl. Applications 4:260. 1968.

2. K. G. Helmer and M. H. Putnam. ANCR-1043. Aerojet Nuclear Co., ldaho Falls, Idaho. 1972. 
RFP-2382

\section{ILLU STR A T ION S}

Figures 1 through 20 


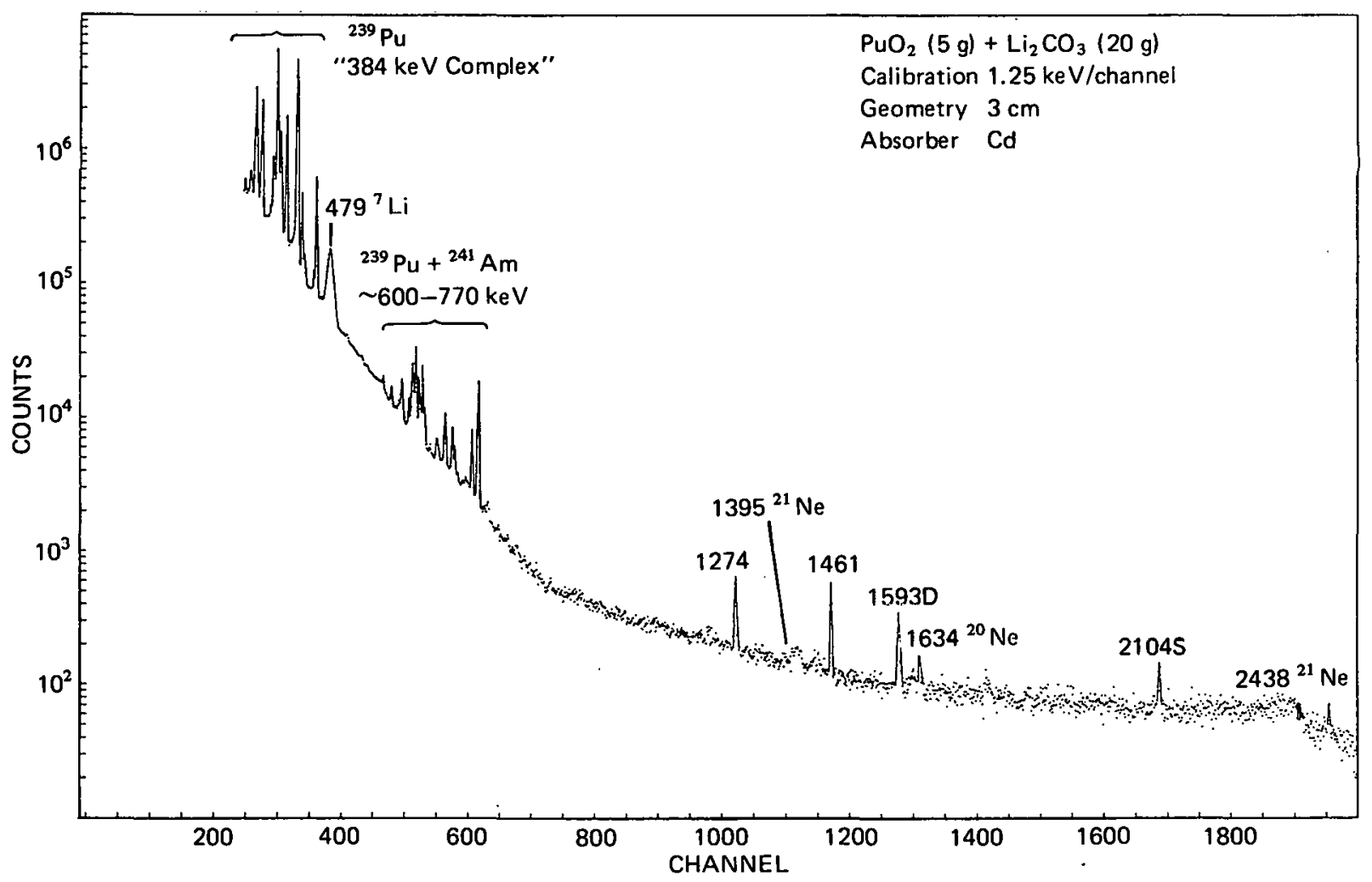

FIGURE 1.

FIGURE 2.

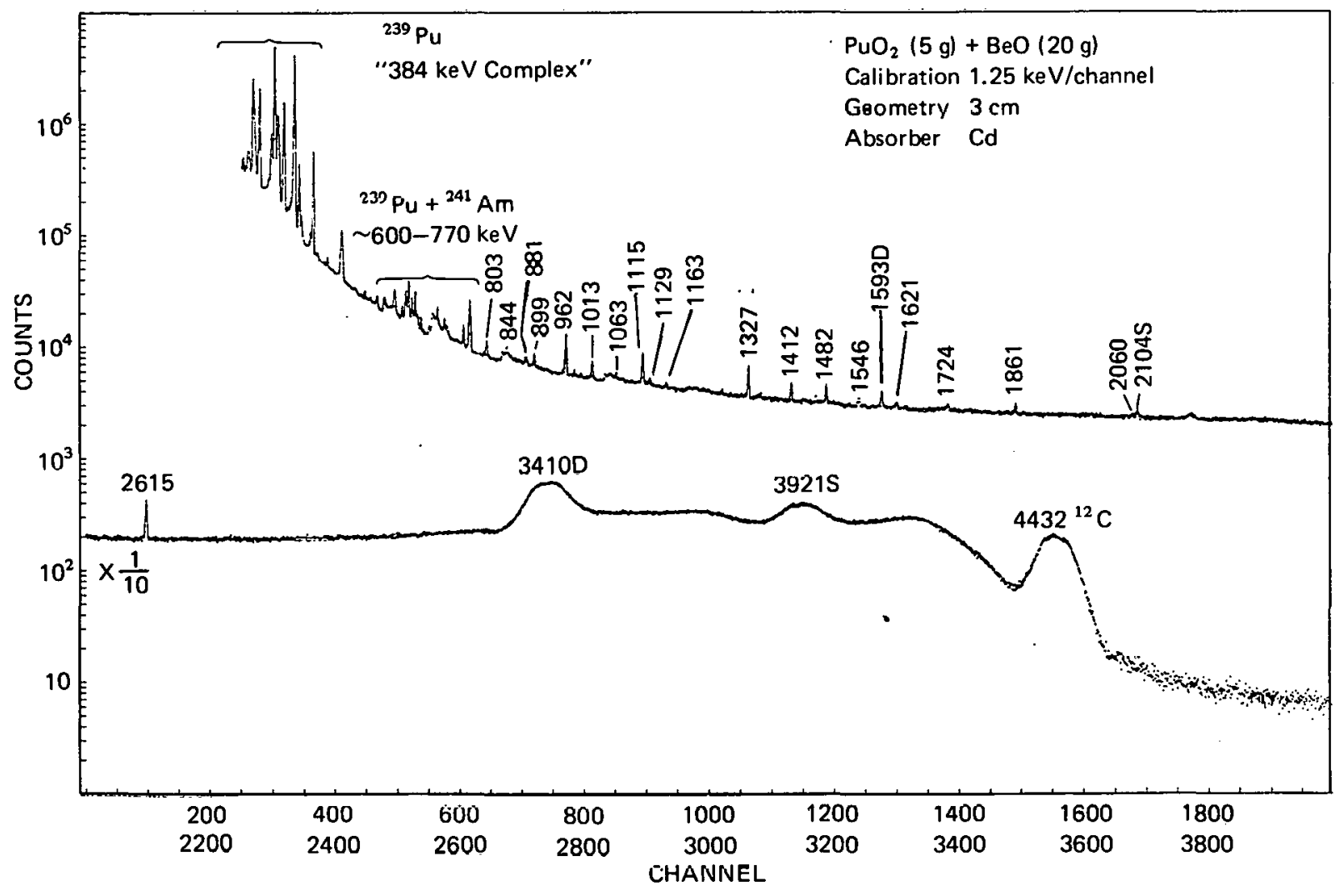




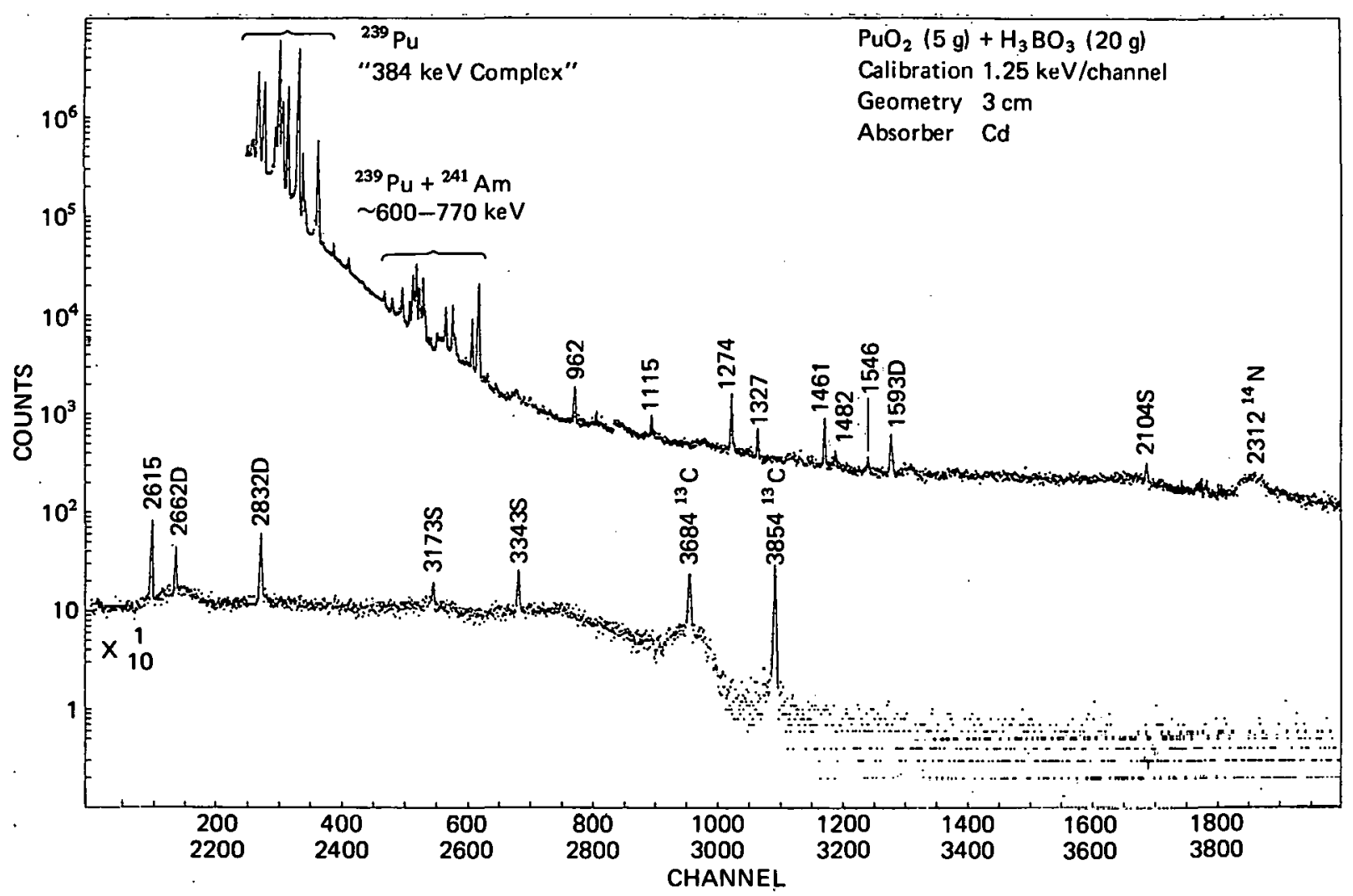

FIGURE 3.

FIGURE 4.

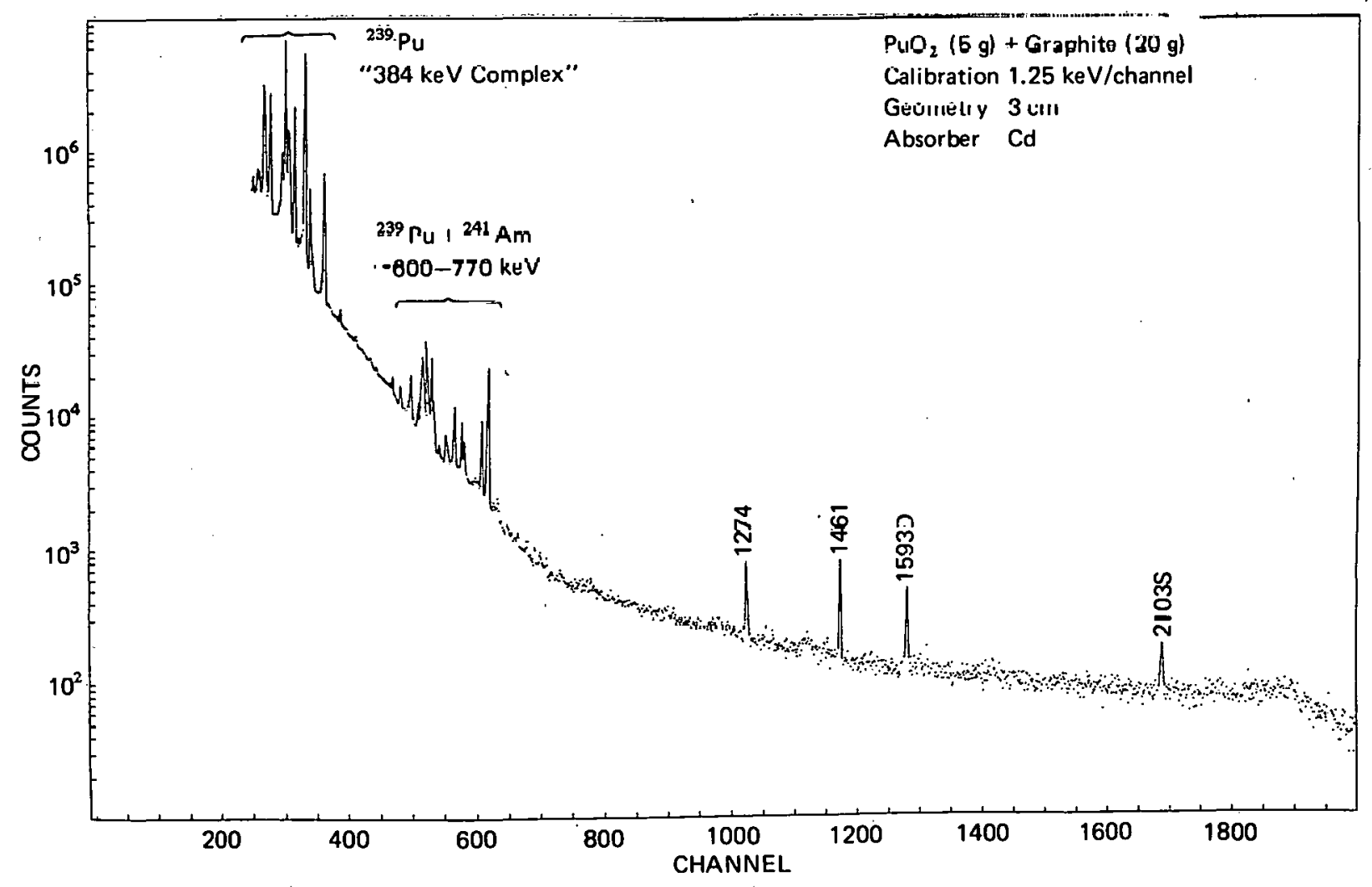




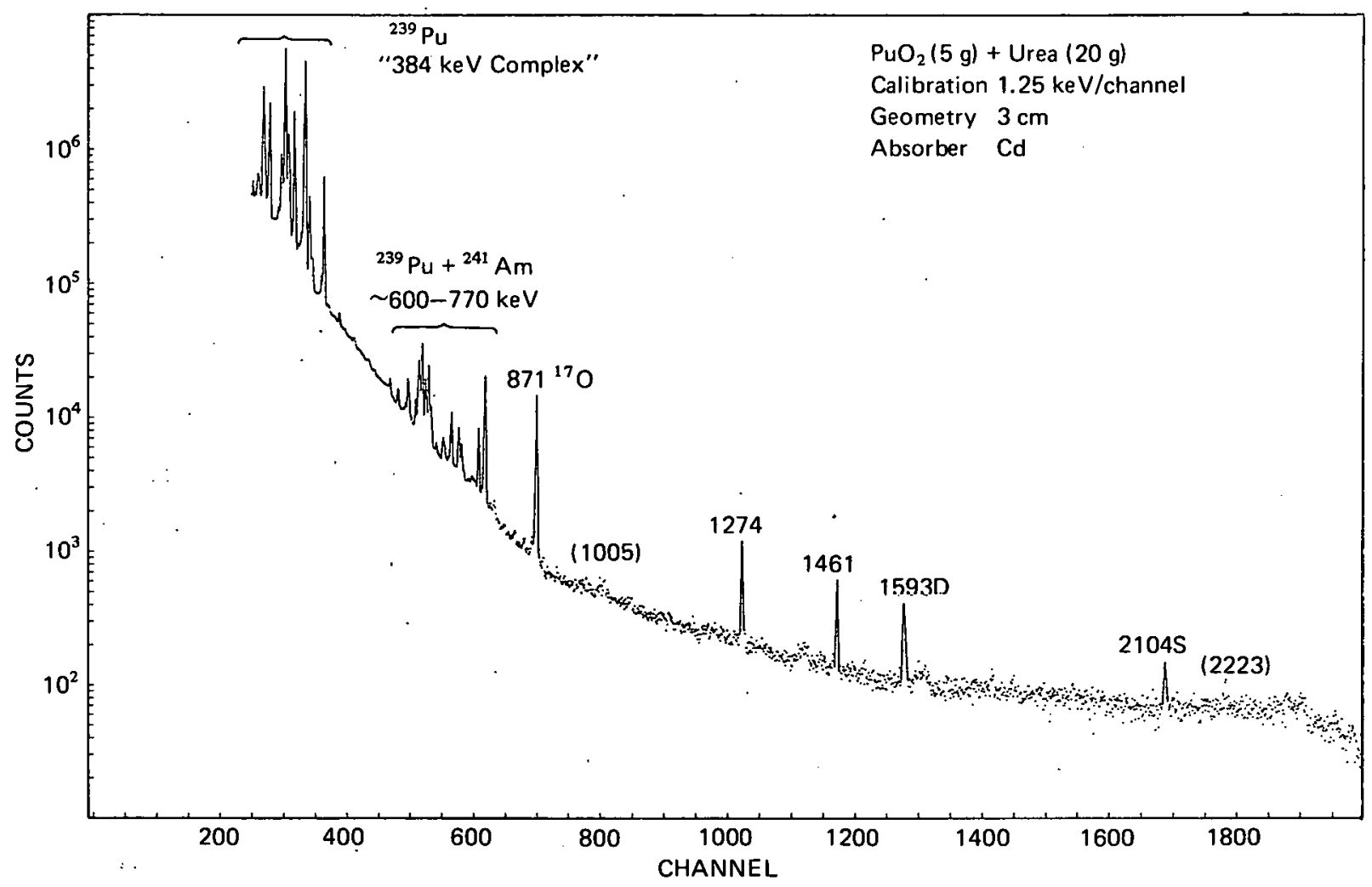

FIGURE 5.

FIGURE 6.

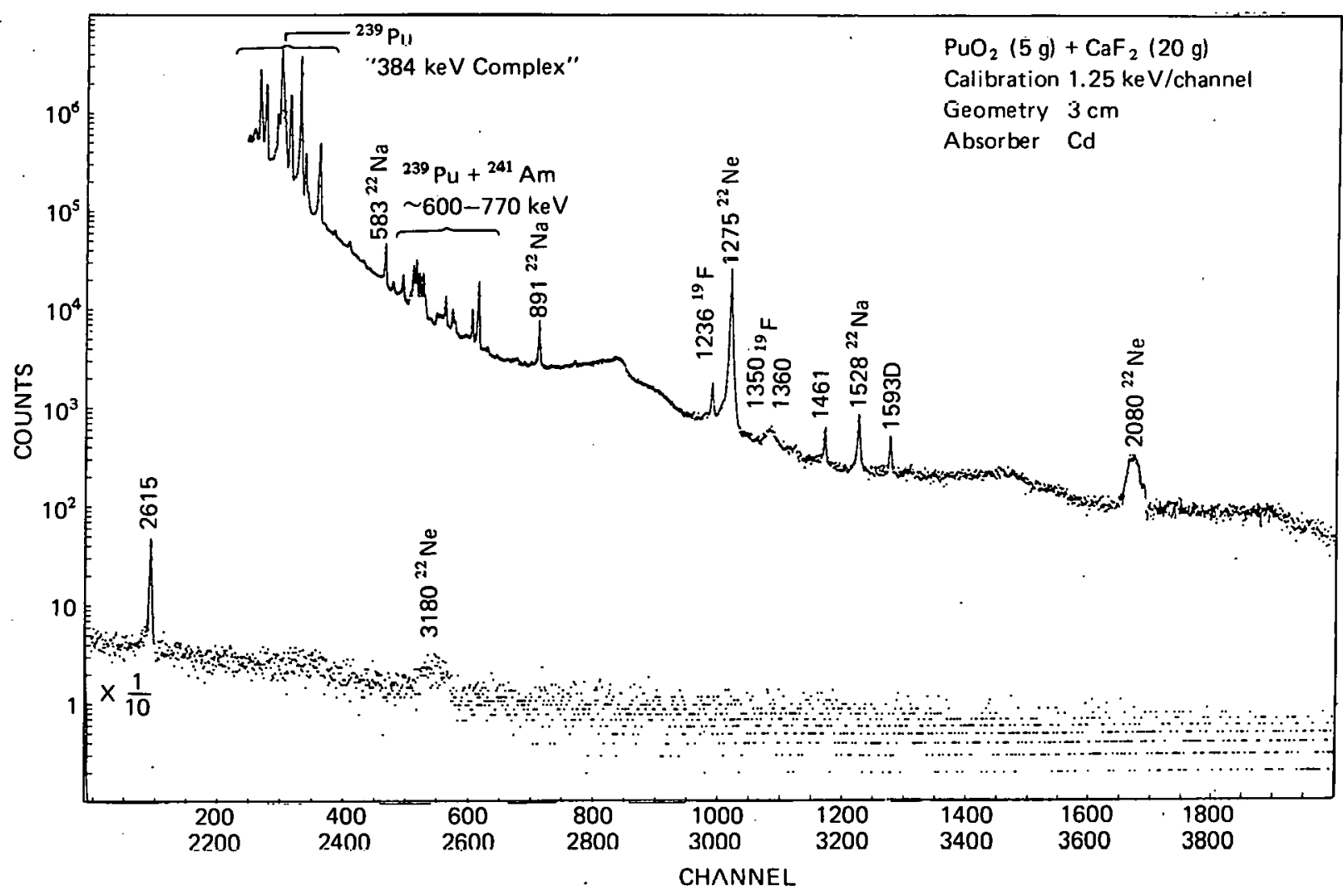




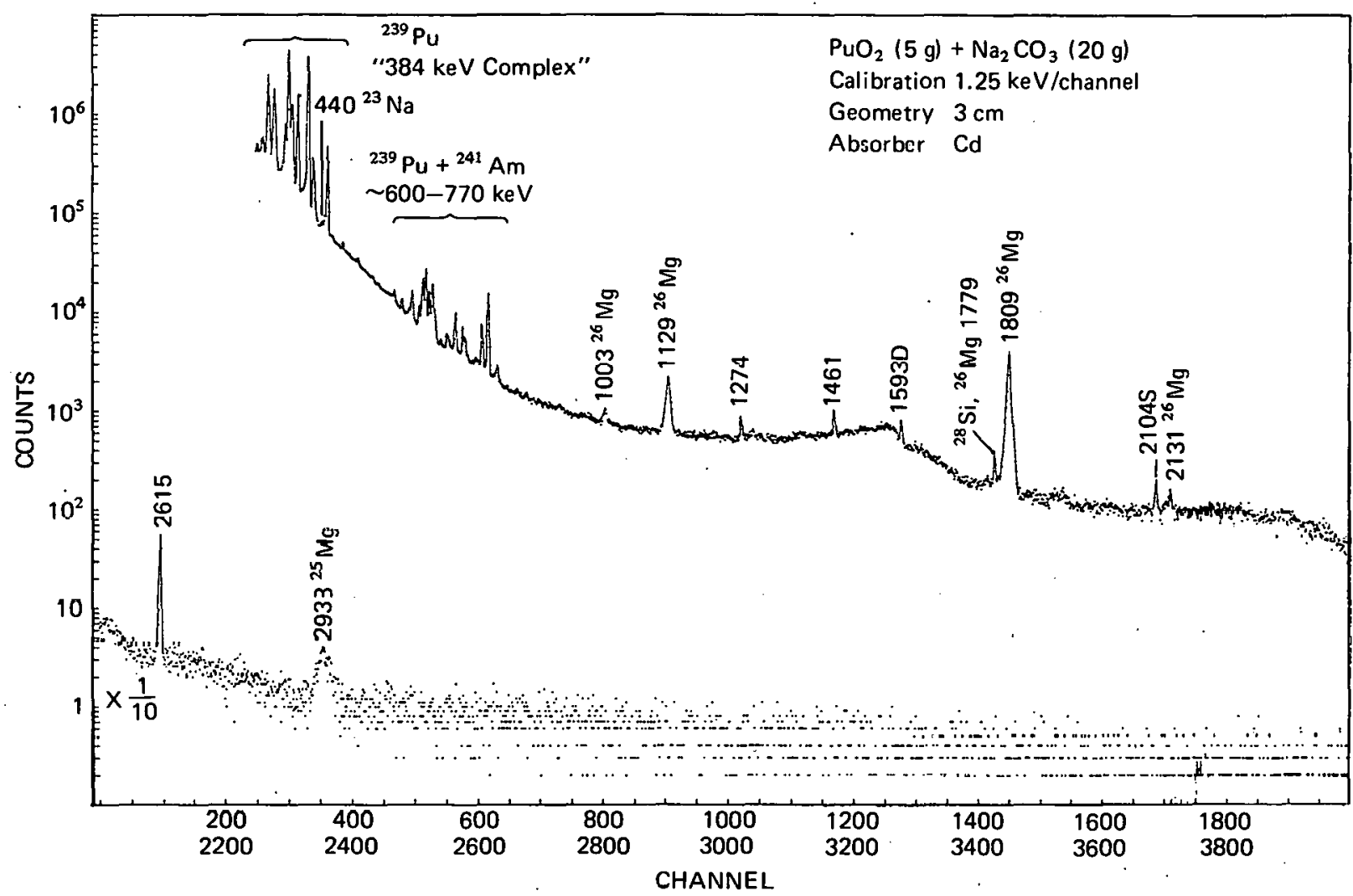

FIGURE 7.

FICIIRF. 8 .

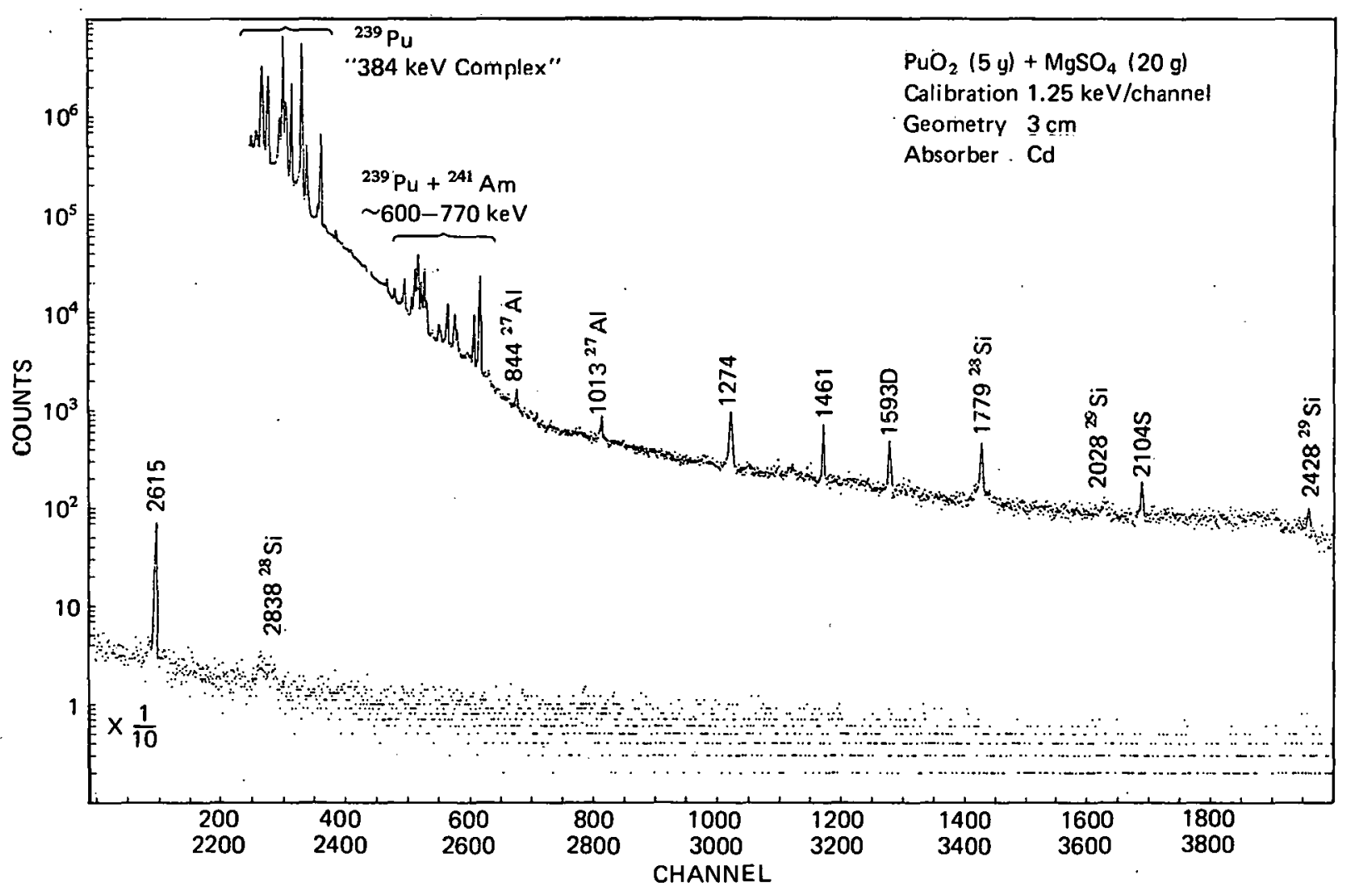




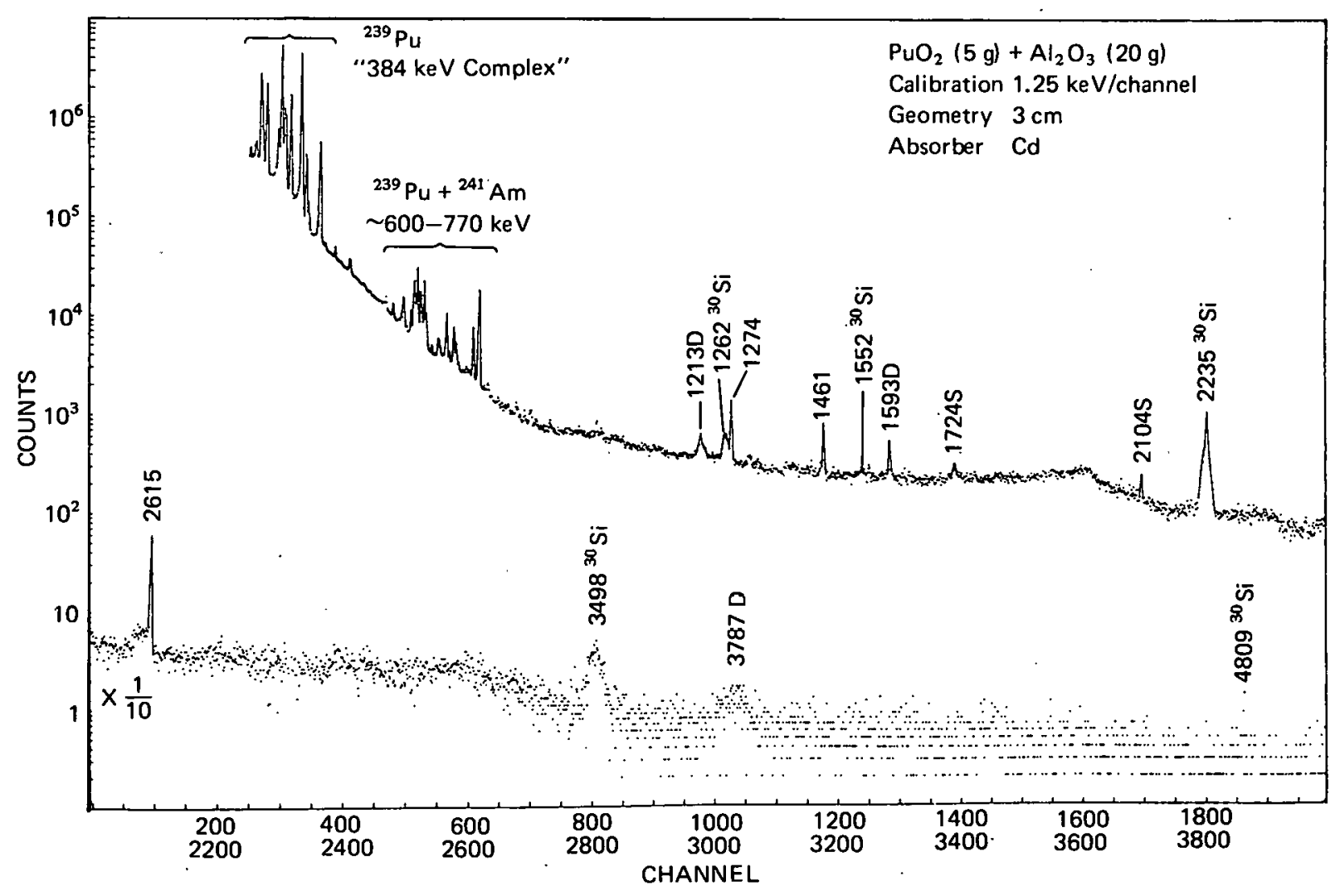

FIGURE 9.

FIGURE 10.

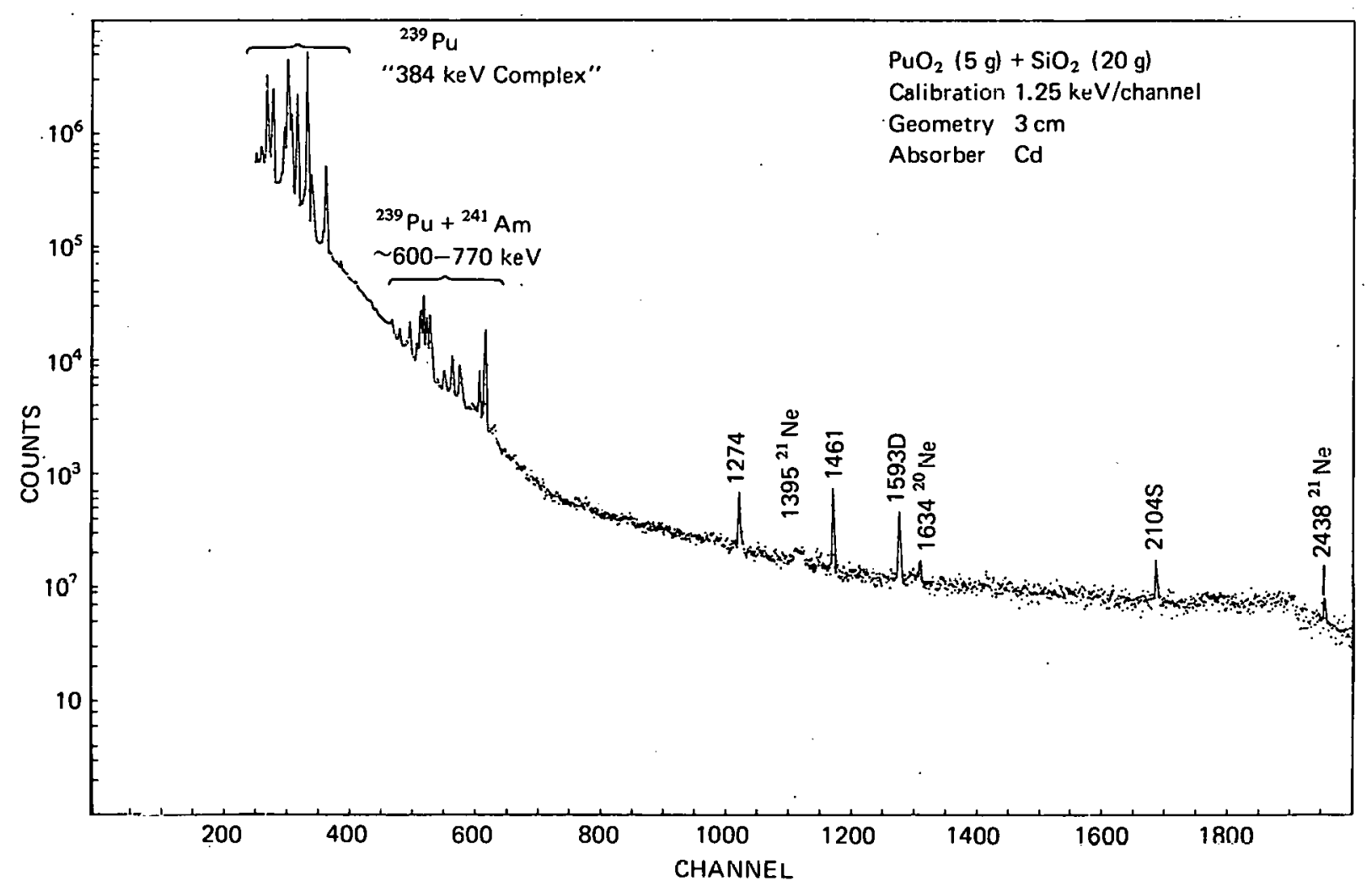




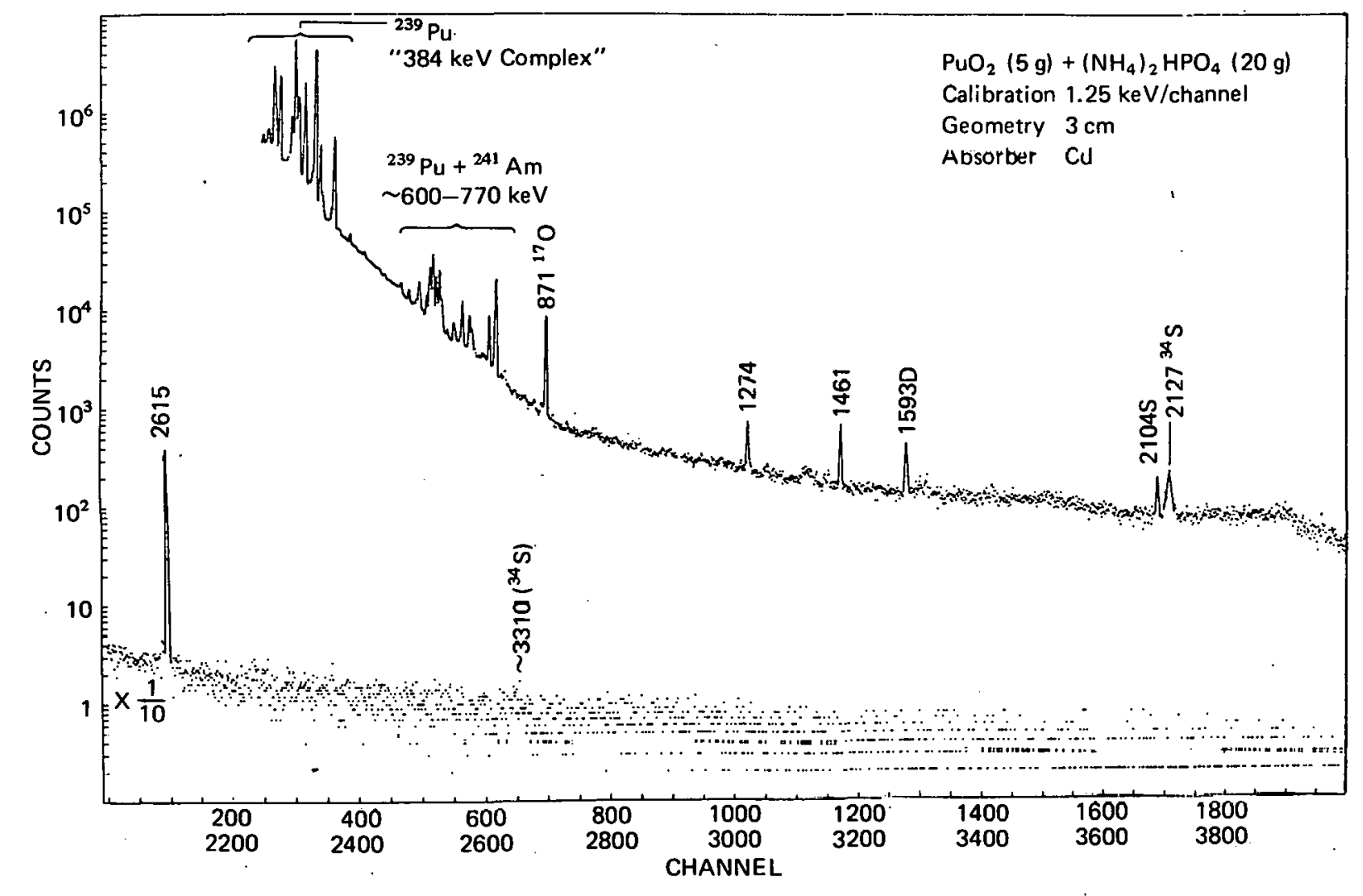

FIGURE 11.

FIGURE 12.

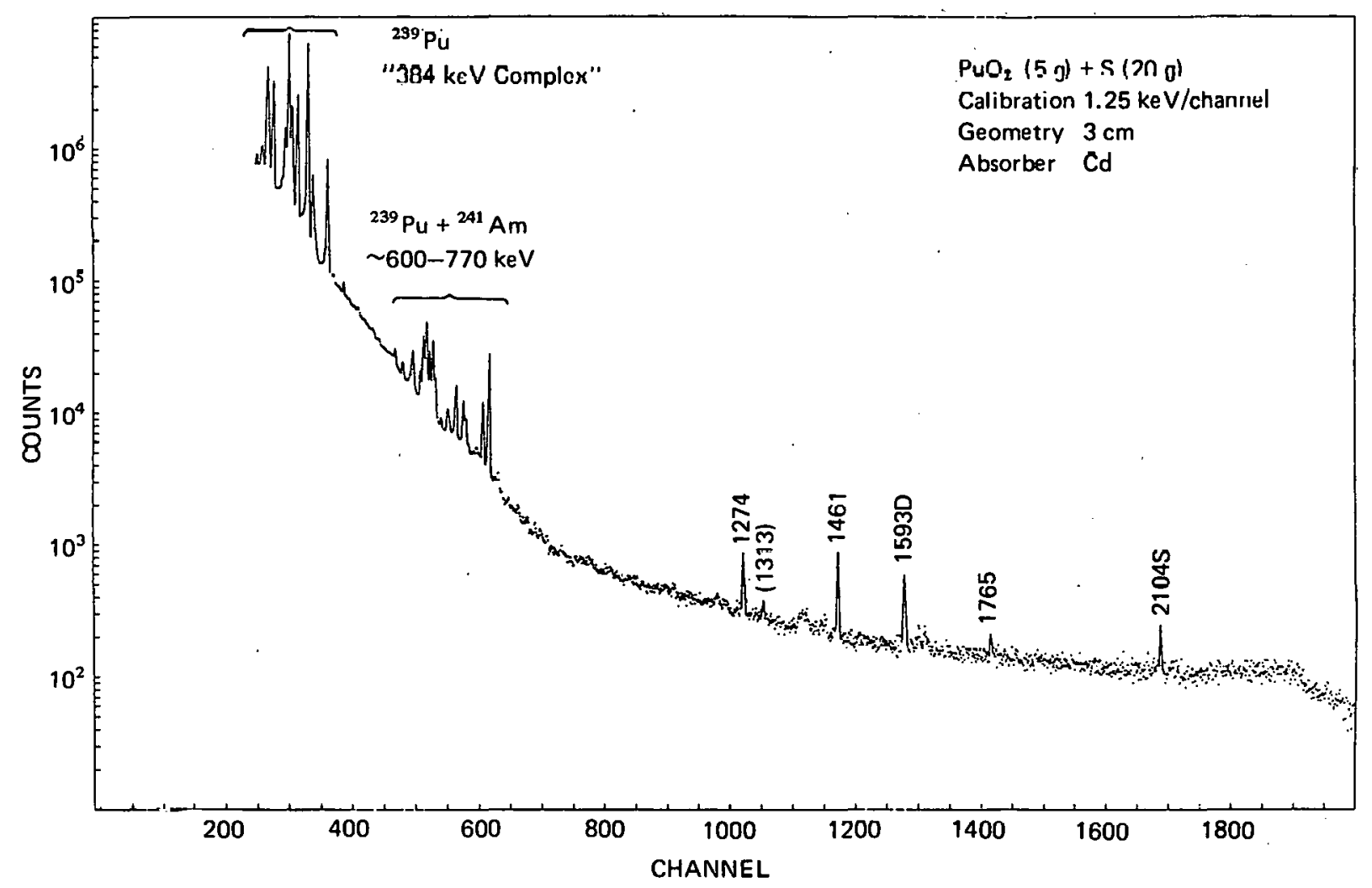




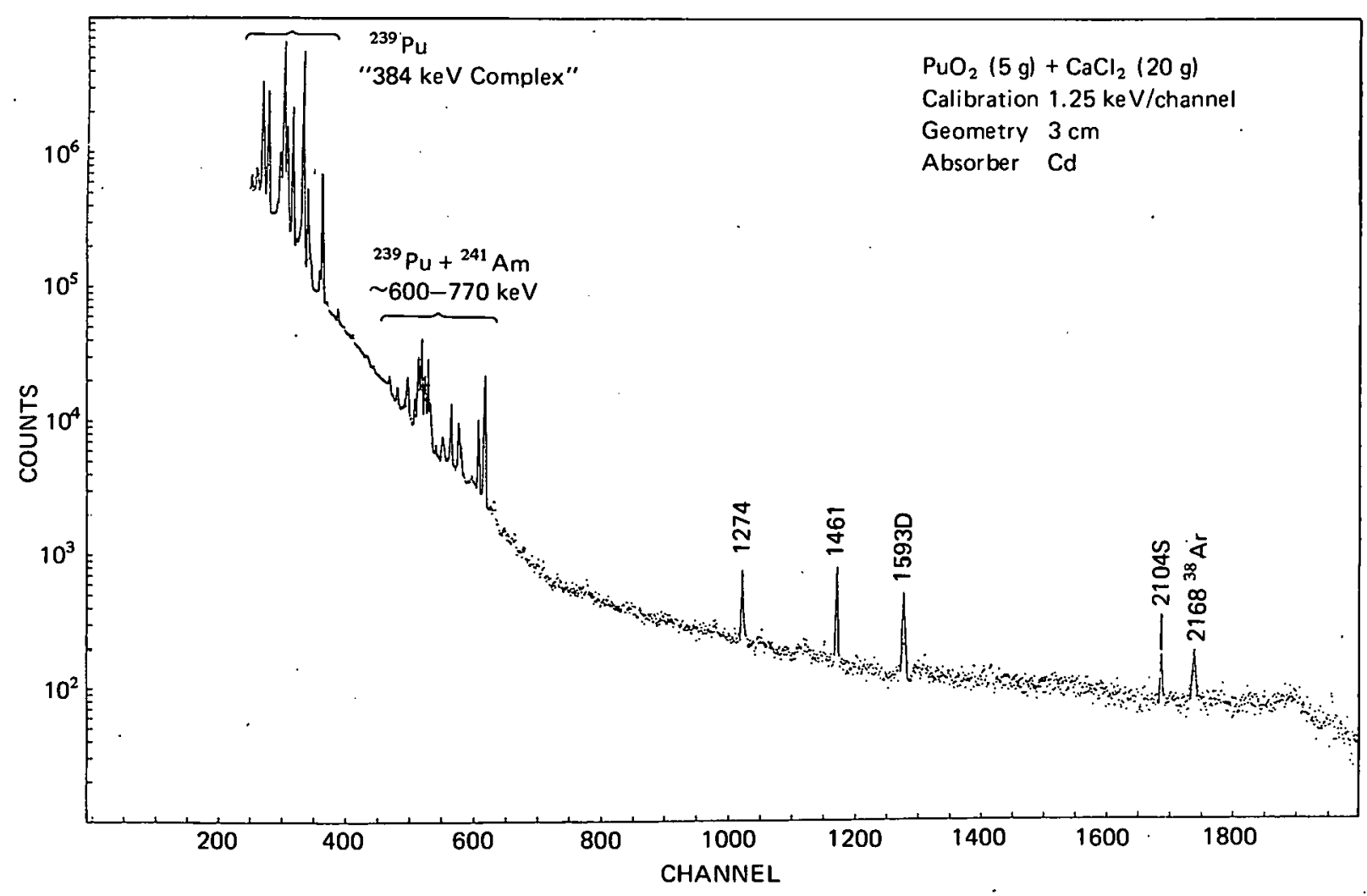

FIGURE 13.

FIGURE 14.

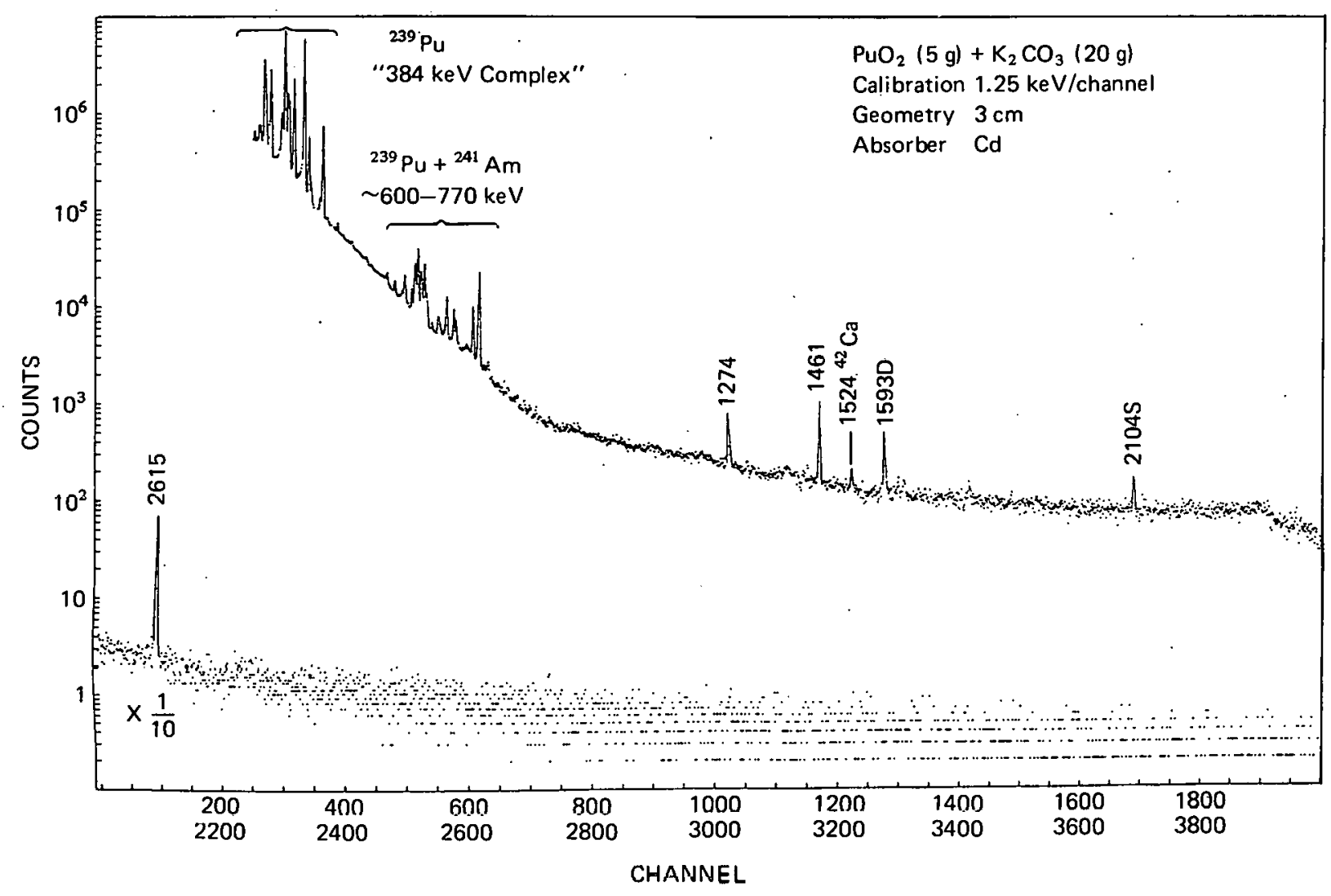




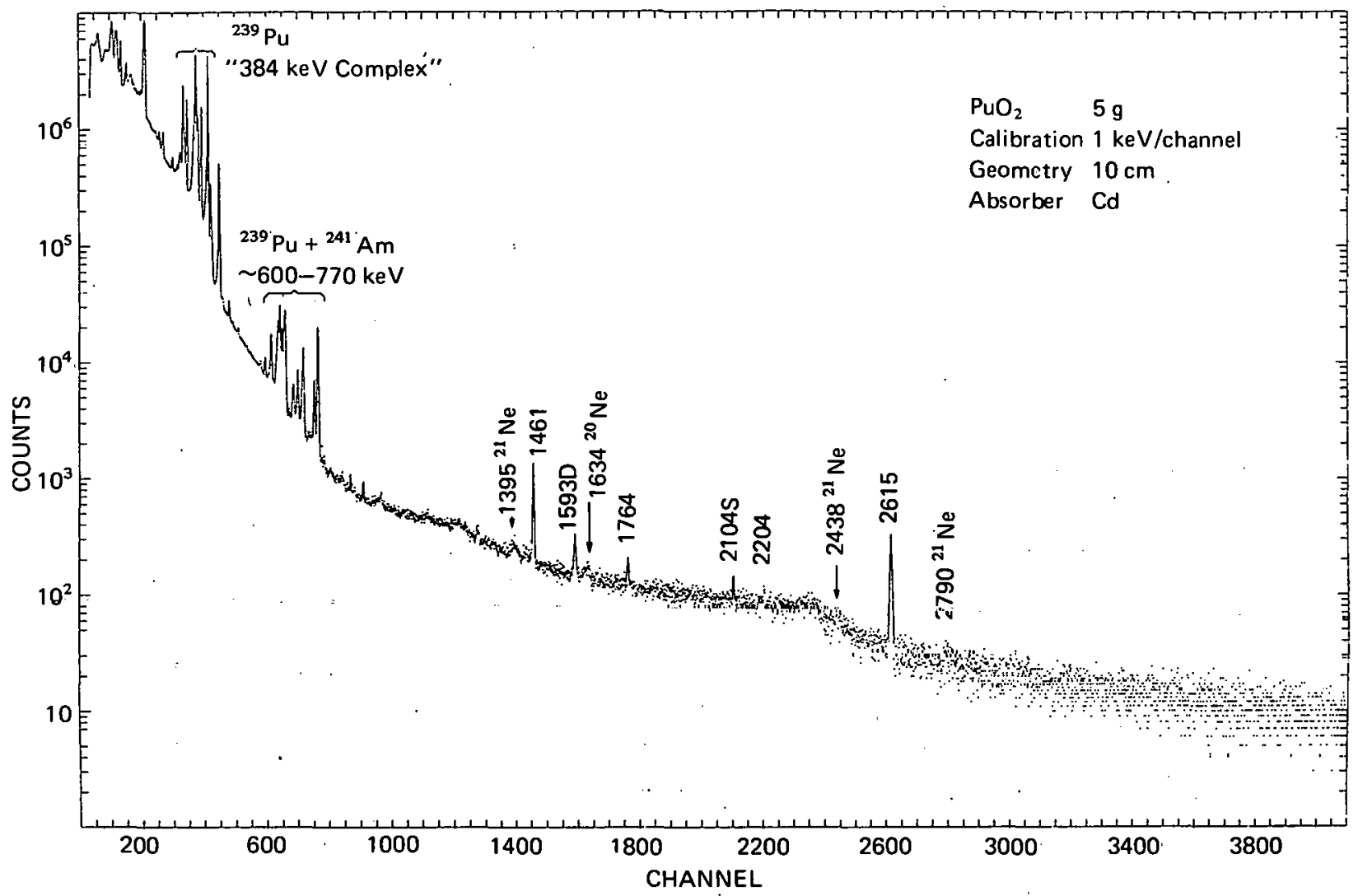

FIGURE 15.

FIGURE 16.

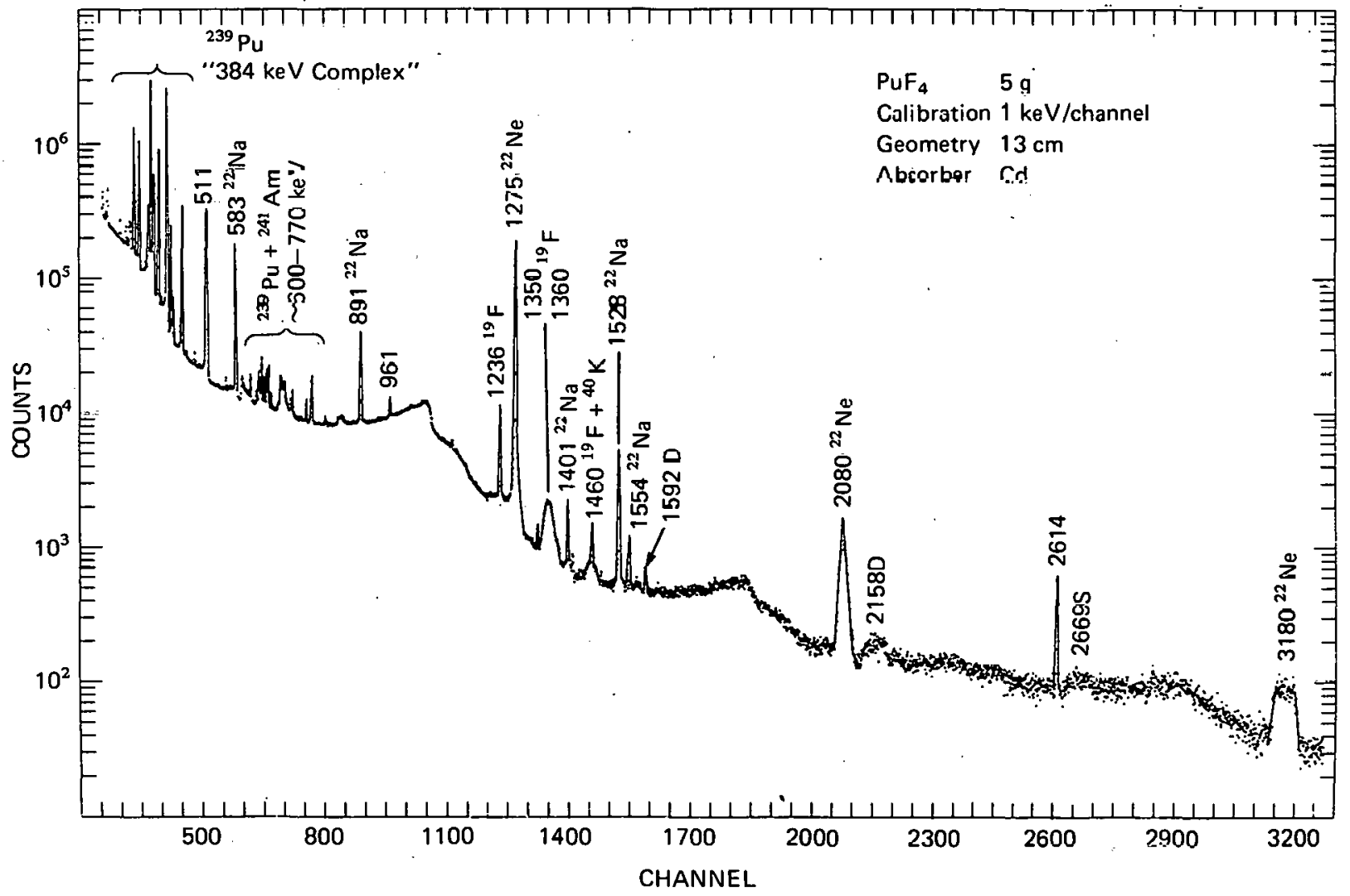




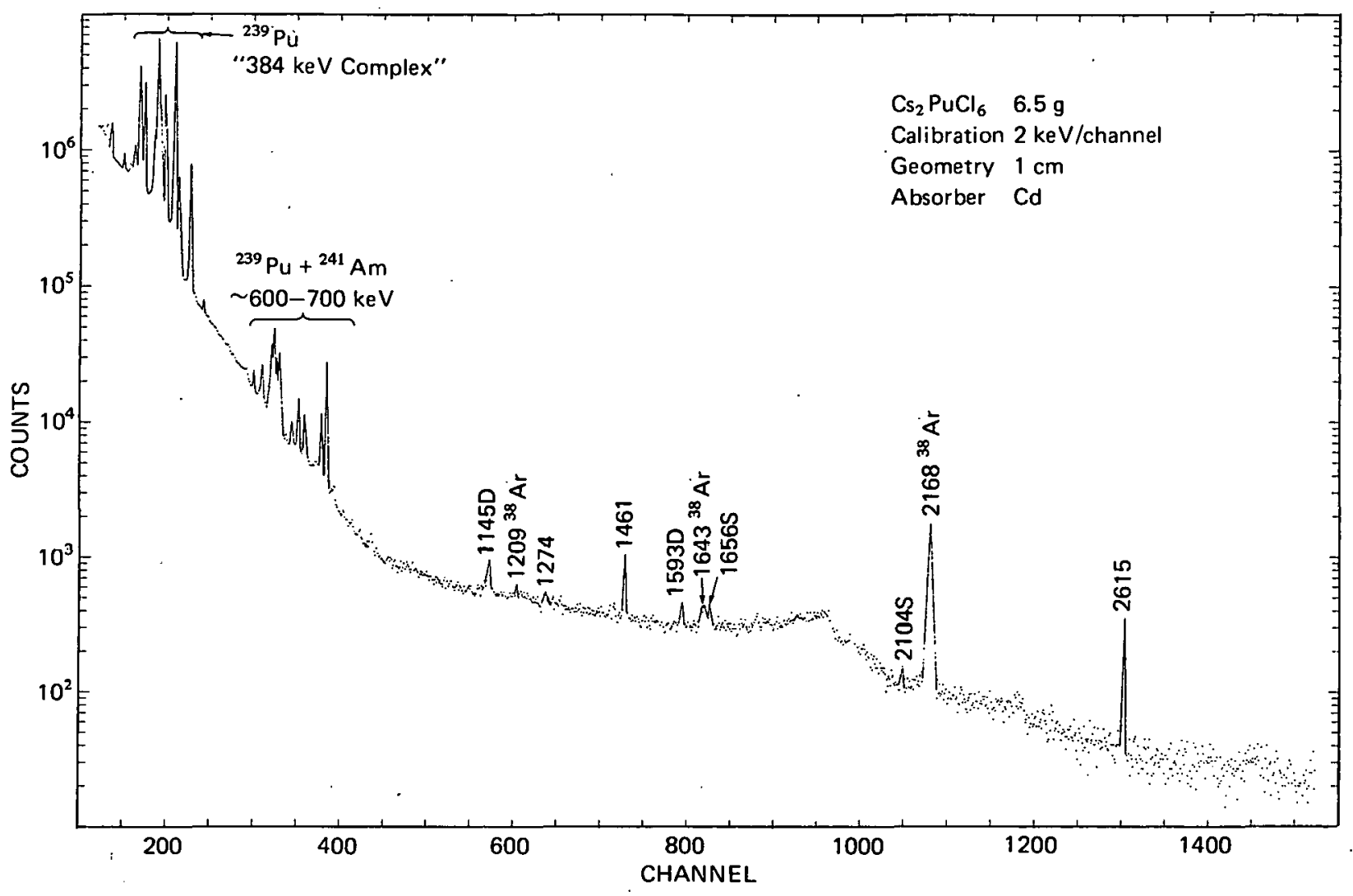

FIGURE 17.

FIGURE 18.

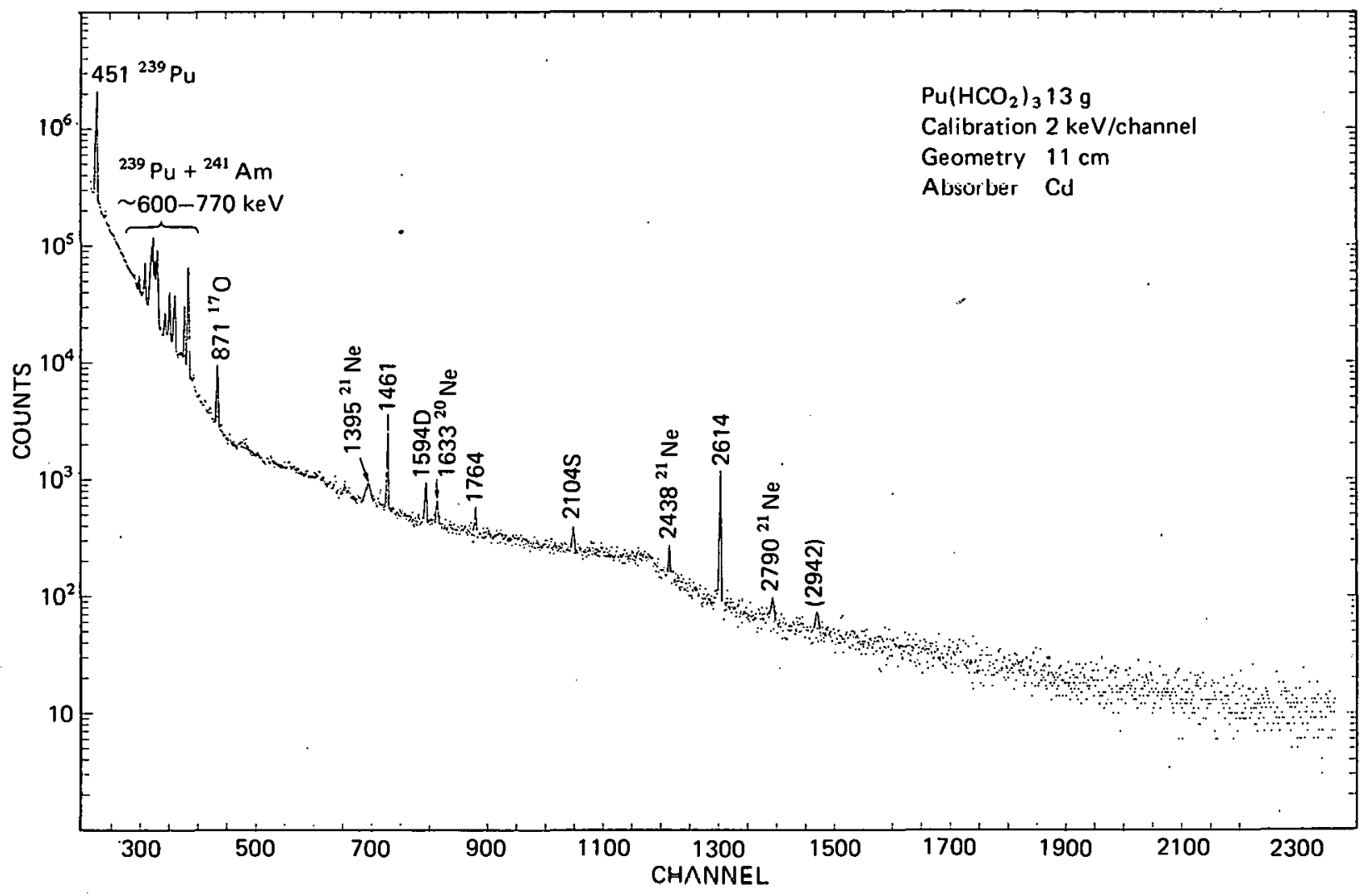




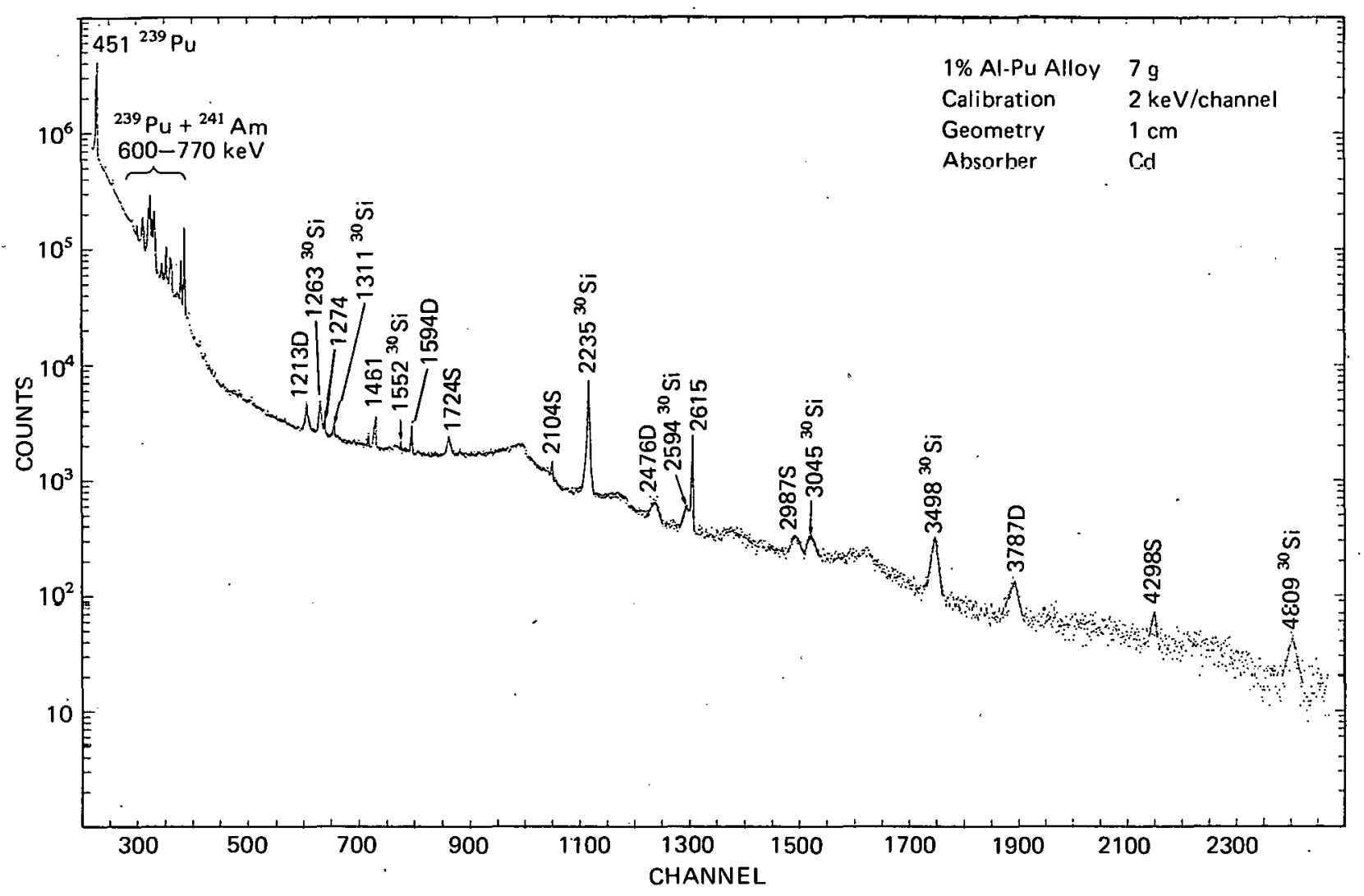

FIGURE 19.

FIGURE 20.

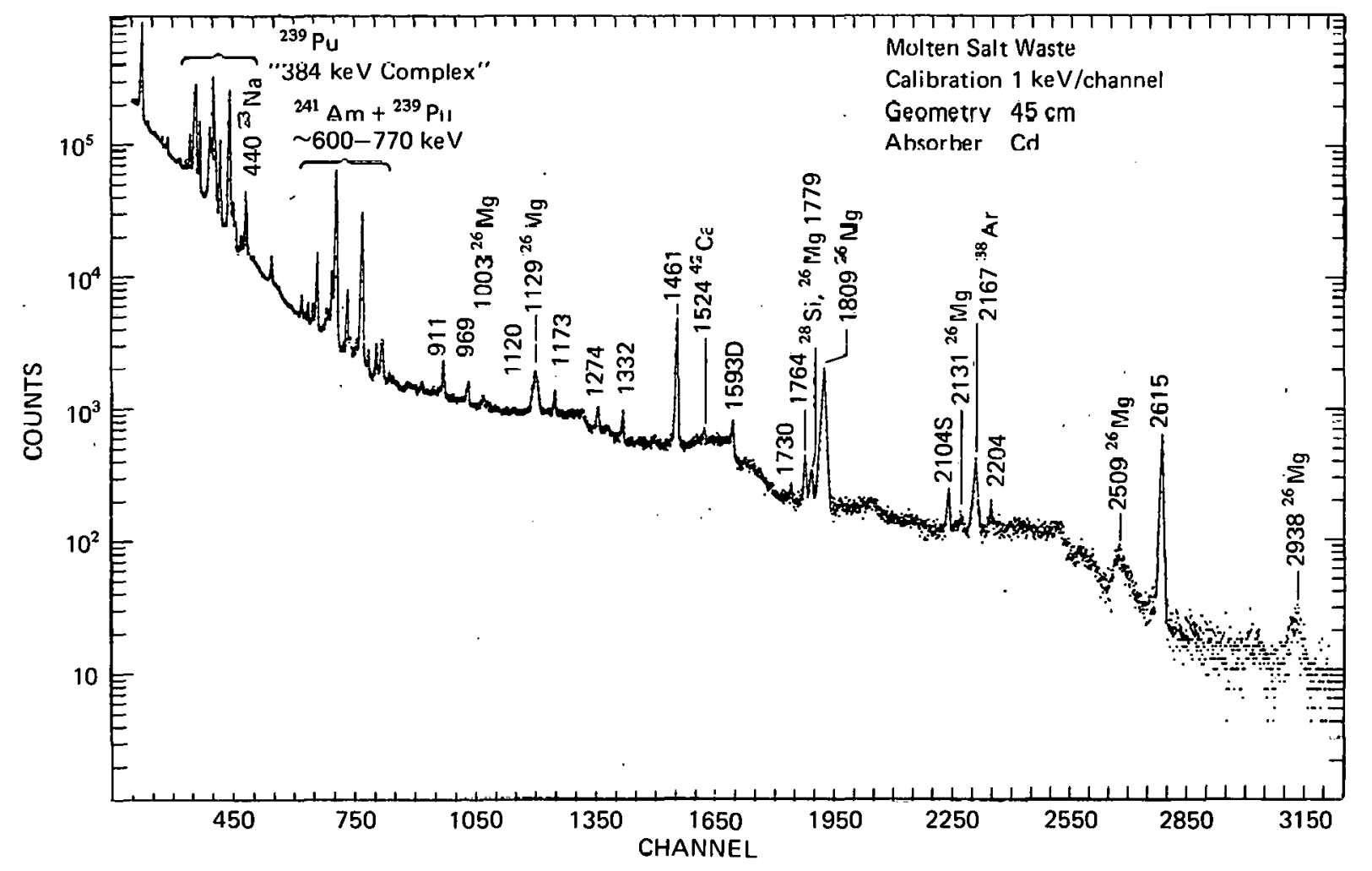

